\title{
An exceptionally well-preserved skeleton of Thomashuxleya externa (Mammalia, Notoungulata), from the Eocene of Patagonia, Argentina
}

\author{
Juan D. Carrillo and Robert J. Asher
}

\begin{abstract}
We describe one of the oldest notoungulate skeletons with associated craniodental and postcranial elements: Thomashuxleya externa (Isotemnidae) from Cañadón Vaca in Patagonia, Argentina (Vacan subage of the Casamayoran SALMA, middle Eocene). We provide body mass estimates given by different elements of the skeleton, describe the bone histology, and study its phylogenetic position. We note differences in the scapulae, humerii, ulnae, and radii of the new specimen in comparison with other specimens previously referred to this taxon. We estimate a body mass of $84 \pm 24.2 \mathrm{~kg}$, showing that notoungulates had acquired a large body mass by the middle Eocene. Bone histology shows that the new specimen was skeletally mature. The new material supports the placement of Thomashuxleya as an early, divergent member of Toxodontia. Among placentals, our phylogenetic analysis of a combined DNA, collagen, and morphology matrix favor only a limited number of possible phylogenetic relationships, but cannot yet arbitrate between potential affinities with Afrotheria or Laurasiatheria. With no constraint, maximum parsimony supports Thomashuxleya and Carodnia with Afrotheria. With Notoungulata and Litopterna constrained as monophyletic (including Macrauchenia and Toxodon known for collagens), these clades are reconstructed on the stem to Euungulata (i.e., Perissodactyla and Artiodactyla). Unconstrained, Bayesian analysis weakly supports the possibility that Thomashuxleya is a stem xenarthran; with Notoungulata and Litopterna constrained as monophyletic, the two clades are recovered as sister to Perissodactyla. Anatomical data sampled thus far for Thomashuxleya, combined with collagen amino acids for Pleistocene meridiungulates, substantially limit the number of possible affinities for endemic South American species among mammals, although ambiguity still remains.
\end{abstract}

Juan D. Carrillo. Paläontologisches Institut und Museum, Universität Zürich. Karl-Schmid-Strasse 4, 8006 Zürich, Switzerland and Department of Zoology, University of Cambridge. Downing Street CB2 3EJ, Cambridge, UK. juan.carrillo@pim.uzh.ch Robert J. Asher. Department of Zoology, University of Cambridge. Downing Street CB2 3EJ, Cambridge, UK. r.asher@zoo.cam.ac.uk

Keywords: South America; Toxodontia; Litopterna; body mass; phylogeny

Submission: 23 January 2017 Acceptance: 30 June 2017

Carrillo, Juan D. and Asher, Robert J. 2017. An exceptionally well-preserved skeleton of Thomashuxleya externa (Mammalia, Notoungulata), from the Eocene of Patagonia, Argentina. Palaeontologia Electronica 20.2.34A: 1-33 palaeo-electronica.org/content/2017/1930-anatomy-and-systematics-of-thomashuxleya-externa-notoungulata 


\section{INTRODUCTION}

South America was isolated during most of the Cenozoic and was home to a highly endemic fauna (Simpson, 1980; Pascual, 2006; Wilf et al., 2013). South American Native Ungulates, or "SANUs" (Welker et al., 2015), were classified in Meridiungulata by McKenna (1975). Meridungulates are a conspicuous faunal element of the South American Cenozoic, with an extensive fossil record that spans the early Paleocene $(\sim 64 \mathrm{Ma}$, Tiupampan South American Land Mammal age or SALMA; Gelfo et al., 2009; Woodburne et al., 2014a, 2014b) to late Pleistocene ( 11-7 ka, Cione et al., 2003; 11-13 ka, Barnosky and Lindsey, 2010). Notoungulata is the major clade within Meridiungulata and exhibits a high taxonomic diversity ( $>140$ genera and 13 families; Croft, 1999), large morphological disparity, wide range of body masses (Giannini and García-López, 2014), different degrees of hypsodonty, and diverse diets (MacFadden, 2005; Townsend and Croft, 2008; Cassini et al., 2011; Madden, 2015). The monophyly of Notoungulata is generally accepted, with Pyrotheria sometimes included (Patterson, 1977; Billet, 2010, 2011) or excluded (Roth, 1903; Cifelli, 1993; Simpson, 1978). Alignments of amino acid residues of alpha 1 and 2 collagen chains support a close relationship of Pleistocene members of Notoungulata (Toxodon) and Litopterna (Macrauchenia) with extant Perissodactyla (Welker et al., 2015). Another analysis of alpha 1 and 2 collagen amino acids also supported Toxodon and Macrauchenia with perissodactyls. However, this study (Buckley, 2015, figure 2) gave likelihood bootstrap support values below 50 for this clade, and (unlike Welker et al., 2015) the alignments from Buckley (2015) are not publicly accessible as of this writing.

Most of the earliest members of the notoungulate radiation in South America are known from dental and isolated postcranial remains (e.g., Horovitz, 2004; Bergqvist, et al., 2007; Shockey, and Flynn, 2007; Lorente et al., 2014; Lorente, 2015). Specimens with associated cranial and postcranial elements are extremely rare. The Isotemnidae (Notoungulata) has been interpreted as a basal group within Toxodontia (Simpson, 1936; Cifelli, 1993). More recent evidence suggests that Isotemnidae could be polyphyletic (Billet, 2011) and defined by plesiomorphic traits among Toxodontia (Simpson, 1967; Billet, 2011).

Remains of Thomashuxleya (Isotemnidae) are among the earliest known associated notoungulate skeletons (Simpson, 1936, 1967). However, the original descriptions of Simpson were idealized and based on a composite skeleton representing three different genera: Thomashuxleya, Anisotemnus, and Pleurostylodon (Simpson, 1967; Shockey and Flynn, 2007). This reduces the value of Simpson's skeletal reconstruction for palaeobiological inference in general and phylogenetic analysis in particular. Thomashuxleya is middle Eocene in age, and our material derives from the Vacan subage of the Casamayoran SALMA, older than the adjacent Barrancan subage (Cifelli, 1985; Gelfo et al., 2009; Kay et al., 1999; Woodburne et al., 2014a). Thomashuxleya has previously been referred to a relatively basal clade within Toxodontia (Billet, 2011), making it particularly relevant to understand the early radiation of notoungulate mammals.

At least 28 mammal taxa are recognized for the Cañadón Vaca local fauna (Cifelli, 1985, table 5; Shockey and Flynn, 2007). Among Isotemnidae (sensu McKenna and Bell, 1997), four species are present: Pleurostylodon similis, Isotemnus primitivus, Thomashuxleya externa, and Anisotemnus distentus (Cifelli, 1985; Shockey and Flynn, 2007).

In this contribution, we describe a specimen consisting of a single individual of Thomashuxleya externa with a well-preserved skull and jaws associated with postcrania from Cañadón Vaca, east of Colhué Huapí Lake in Chubut Province, Argentina (Figure 1) (Simpson, 1948; Cifelli, 1985). Parts of most elements of the skeleton are represented, including the skull, mandible, vertebrae, fore- and hind-limbs, shoulder, and pelvic girdles. Associated remains of other individuals found at the same locality include a partially articulated manus. This discovery provides an unusually complete anatomical basis to study the biology and phylogenetic position of an early member of toxodont notoungulates.

\section{MATERIALS AND METHODS}

\section{Institutional Abbreviations}

MPEF-PV: Museo Paleontológico Egidio FeruglioPaleontolgía de Vertebrados, Trelew, Chubut, Argentina; AMNH: American Museum of Natural History, New York, USA; MNHN: Muséum national d'Histoire naturelle, Paris, France.

\section{Anatomical Description}

We follow Smith and Dodson (2003) for the dental orientation, where mesial and distal designate the tooth surface directions facing forward and away from the mandibular symphysis, respec- 

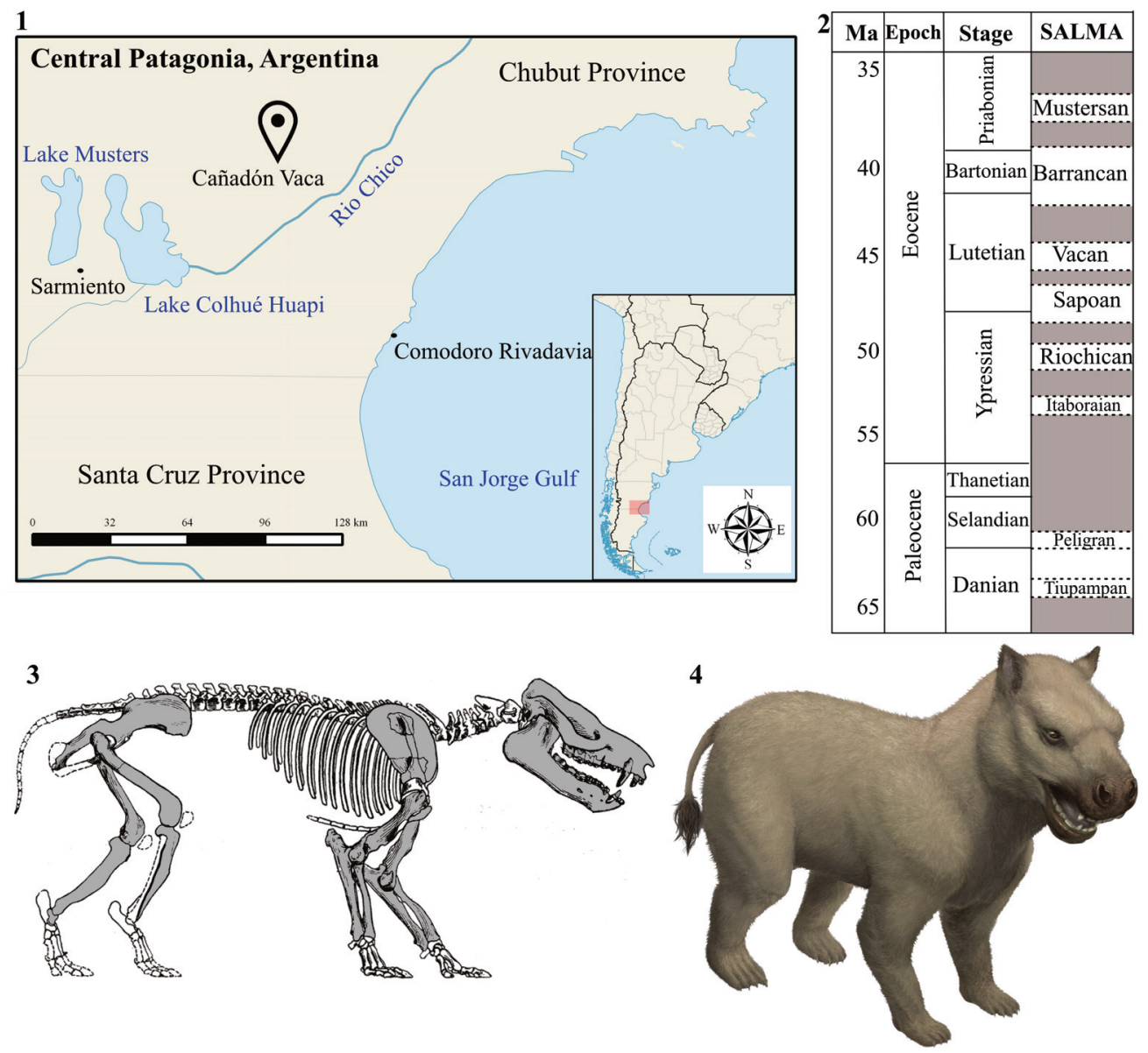

FIGURE 1. Geographical and stratigraphical occurrence of MPEF-PV 8166. 1 location of Cañadón Vaca, Chubut, Argentina; 2 Paleogene time table and South American Land Mammal Ages (SALMAs) after (Woodburne et al. 2014a,b); 3 skeletal restoration of Thomashuxleya modified from Simpson (1936); 4 artistic reconstruction of Thomashuxleya externa (by Stjepan Lukac).

tively. We follow Madden (1990) for the notoungulate dental terminology and Cerdeño et al. (2012) for the orientation of the postcranial bones.

The skull, mandible, and dentition of MPEFPV 8166 were compared with different isotemnids as reviewed by Simpson (1967) and the original descriptions of Ameghino (1901). The postcranial elements of MPEF-PV 8166 were compared with AMNH 28905 referred to $T$. externa and originally described by Simpson (1936, 1967), and recently reviewed by Shockey and Flynn (2007). In addition, O'Leary et al. (2013) included much of the anatomy of published specimens in their phylogenetic study of living and fossil mammals. We made additional comparisons with other isotemnid specimens as described by Simpson $(1936,1967)$ and reviewed by Shockey and Flynn (2007), and also with other basal notoungulates (Bergqvist et al., 2007; Lorente et al., 2014; Lorente, 2015). Our associated remains of Thomashuxleya (primarily
MPEF-PV 8166) provided the basis for revising and scoring new postcranial character states for $T$. externa using the morphological dataset of O'Leary et al. (2013). Our revised character states have been accessioned in MorphoBank (Project 2084).

\section{Body Mass Estimation}

We used the specimen to test the congruence between body mass estimations with regression equations from the crania and postcrania. We took standard linear measurements of the limb bones, skull, and dentition with calipers to the nearest 0.1 $\mathrm{mm}$. When the right and left limb bones could be measured, we used the average. In order to generate body mass estimations for MPEF-PV 8166, we used craniodental regression equations selected from Janis (1990) and multivariate regression algorithms following Mendoza et al. (2006). Postcranial regression equations follow Scott (1990) for the 
limb bones and Tsubamoto (2014) for the astragalus (see Appendix 1-2).

The regression equations were selected based on their high $r^{2}$ value $(>0.90)$, a percentage of predicted error (PE) below $40 \%$, and presence of relevant anatomy in MPEF-PV 8166. Janis (1990) and Scott (1990) obtained regression equations using a dataset of extant ungulates and these have been used previously to estimate body mass for notoungulates (e.g., Cassini et al., 2012;Elissamburu, 2012). The dataset of Tsubamoto (2014) included several orders of living mammals.

To obtain body mass estimates we log-transformed (base 10) the body mass estimates from the regression equations from Janis (1990) and Scott (1990), and used a natural log transformation for Tsubamoto (2014). We compared the results from the different subsets of measurements, namely skull, teeth, long bones, and astragalus. We calculated the statistical descriptors and moments (minimum, maximum and mean values, median, mode, skewness, and kurtosis). We resampled with replacement (i.e., bootstrap) with 1000 replications and calculated 95\% confidence intervals (Cl) using R (R Core Team, 2016).

\section{Bone Histology}

We took a cortical slice of $1 \mathrm{~cm}$ from the midshaft of the right femur. The section was embedded in Araldite ${ }^{\circledR} 2020$ prior to sawing and grinding. For the production of thin sections we followed protocols of Straehl et al. (2013). The section (PHZ 950) was observed in normal transmitted and crosspolarized light using a Leica DM 2500 M microscope equipped with a Leica DFC 420 C digital camera. In order to infer the bone microstructure, we also took a photograph of the complete section and transformed to a binary image with Affinity Designer ${ }^{\circledR} 1.5 .4$, where black represents the bone and white the cavities.

\section{Phylogenetic Analysis}

Relationships of Thomashuxleya within Notoungulata. To study the phylogenetic relationship of Thomashuxleya within Isotemnidae, and with other Paleogene notoungulates, we added the information of the new Thomashuxleya specimen (MPEF-PV 8166) to the character matrix of Deraco and García-López (2015). The matrix includes 68 taxa (59 of which are notoungulates) and 146 craniodental characters. We ordered 10 characters, following Deraco and García-López (2015); two others (37 and 119) ordered by them are binary. Searches used 500 replicates of random addition sequence, holding 10 trees per replication, using tree bisection reconnection (TBR) for branch swapping.

Relationships of Thomashuxleya within Placentalia. Postcranial characters were scored for the almost complete Thomashuxleya externa specimen (MPEF-PV 8166), using the morphological dataset of O'Leary et al. (2013; Morphobank project 773); cranial characters were the same as in O'Leary et al. (2013). The specimens used by O'Leary et al. (2013) to score the craniodental characters were referred to $T$. externa by Simpson (1967) and are not associated with postcranial remains. This resulted in 3660 craniodental and postcranial characters for 87 taxa, available in MorphoBank (Project 2084). We concatenated the morphological dataset with the amino acid alignment of Meredith et al. (2011; TreeBase number S11872), which comprises 11010 amino acids for 169 taxa, and the collagen alignment of Welker et al. (2015), with 2028 amino acids for 77 taxa. For the phylogenetic analysis, we combined the morphological and amino acid data using $\mathrm{R}$ ( $\mathrm{R}$ Core Team, 2016), merging species of the same genus and where necessary coding data as absent for fossils (e.g., for most sequence data). To increase the analytical tractability of our dataset, we excluded non-mammals, living mammals with more than $50 \%$ missing data, non-placental fossils, and fossils with over $90 \%$ missing data (except meridiungulates) from our morphological dataset.

For the parsimony analysis, we applied parsimony as the optimality criterion in TNT (Goloboff et al., 2008a), PAUP 4.0a150 (Swofford, 2002), and PAUPrat (Sykes and Lewis, 2001) to a dataset consisting of 182 taxa and 16698 characters (13038 amino acids and 3660 morphological characters). All characters were unordered. We explored equal weights and extended implied weighting; the latter weights the two character sets (amino acids and morphology) using their average homoplasy (Goloboff et al., 2008b, Goloboff, 2014). In order to account for characters with many missing entries that would received artificially high implied weights, we used the command "xpiwe (*", which sets a concavity value $(k)$ according to the number of missing entries (Goloboff, 2014). In addition to our unconstrained analyses, we also explored a number of backbone constraints. Following Tarver et al. (2016) we constrained monophyly of Atlantogenata (Xenarthra + Afrotheria) and Boreutheria (Laurasiatheria + Euarchontoglires) as shown in Tarver et al. (2016, figure 1). We also explored the impact of constraining 1) monophyly 
of each meridiungulate clade in our sample (i.e., the two notoungulates and two litopterns) and 2) all six meridiungulates. We compared the resulting trees of the unconstrained and constrained analyses using a Wilcoxon rank sum test in PAUP* (Swofford, 2002). Parsimony searches included 500 replicates of random addition sequence, holding 10 trees per replication, using tree bisection reconnection (TBR) for branch swapping.

To make Bayesian searches tractable given our available computing resources, we further decreased the number of living taxa to those under $25 \%$ missing data (except meridiungulates), leaving 51 taxa. We obtained partitioning schemes and substitution models for the protein alignment with Partition Finder Protein v1.1.0 using the strict hierarchical clustering algorithm and the Bayesian Information Criterion for model selection (Lanfear et al., 2012). The best model partition scheme resulted in 20 partitions (out of 22 total coding genes) and assigned the JTT+G model for each amino acid partition and the MTMAM $+G$ model for the collagen alpha 1 and 2. We used the standard discrete model implemented by MrBayes (Ronquist et al. 2011) for the morphological characters (Table 1). The dataset was analysed with MrBayes (Ron- quist et al., 2012) and BEAGLE to utilize both GPU and CPU during searches. We used Tracer (Rambaut et al., 2014) for the visualisation and diagnostics of the MCMC output. We ran two analyses, one unconstrained and one constraining monophyly of the two notoungulates and two litopterns in our sample, as described above.

We used three runs of $3,000,000$ generations with five chains (four heated and one cold) for the unconstrained analysis and two runs of $3.500,000$ generations with four chains (three heated and one cold) for the constrained analysis. We sampled every 1000 generations, and use a temperature of 0.5 .

\section{RESULTS}

\section{Systematic Paleontology}

NOTOUNGULATA Roth, 1903

ISOTEMNIDAE Ameghino, 1897

Thomashuxleya Ameghino, 1901

Type species. Thomashuxleya rostrata Ameghino, 1901, by original designation

Thomashuxleya externa (Ameghino, 1901)

Thomashuxleya artuata Ameghino, 1901;

TABLE 1. Best partition scheme for Bayesian analysis as obtained from Partition Finder (Lanfear et al., 2012).

\begin{tabular}{|c|c|c|}
\hline Best model & Subset partitions & Subset sites \\
\hline $\mathrm{JTT}+\mathrm{G}$ & TTN & $1-1479$ \\
\hline $\mathrm{JTT}+\mathrm{G}$ & CNR1 & $1480-1814$ \\
\hline $\mathrm{JTT}+\mathrm{G}$ & $\mathrm{BCHE}$ & $1815-2146$ \\
\hline $\mathrm{JTT}+\mathrm{G}$ & EDG1 & $2147-2466$ \\
\hline $\mathrm{JTT}+\mathrm{G}$ & RAG1 & $2467-3066$ \\
\hline $\mathrm{JTT}+\mathrm{G}$ & RAG2 & $3067-3215$ \\
\hline $\mathrm{JTT}+\mathrm{G}$ & ATP7A & $3216-3444$ \\
\hline $\mathrm{JTT}+\mathrm{G}$ & TYR1 & $3445-3587$ \\
\hline $\mathrm{JTT}+\mathrm{G}$ & Adora3 & $3588-3698$ \\
\hline $\mathrm{JTT}+\mathrm{G}$ & BDNF & $3699-3885$ \\
\hline $\mathrm{JTT}+\mathrm{G}$ & ADRB2 & $3886-4153$ \\
\hline $\mathrm{JTT}+\mathrm{G}$ & PNOC & $4154-4260$ \\
\hline $\mathrm{JTT}+\mathrm{G}$ & $A 2 A B$ & $4261-4543$ \\
\hline $\mathrm{JTT}+\mathrm{G}$ & BRCA1, BRCA2 & $4544-5574,5575-7256$ \\
\hline $\mathrm{JTT}+\mathrm{G}$ & APOB, DMP1 & $7257-7710,9718-10592$ \\
\hline $\mathrm{JTT}+\mathrm{G}$ & GHR & $7711-8026$ \\
\hline $\mathrm{JTT}+\mathrm{G}$ & VWF & $8027-8417$ \\
\hline $\mathrm{JTT}+\mathrm{G}$ & ENAM & $8418-9717$ \\
\hline $\mathrm{JTT}+\mathrm{G}$ & IRBP & $10593-11010$ \\
\hline MTMAM+G & Collagen alpha 1 and 2 & $11011-13038$ \\
\hline Standard discrete & Morphology & $13039-16698$ \\
\hline
\end{tabular}


TABLE 2. Skeletal elements of isotemnid specimens from Cañadón Vaca.

\begin{tabular}{|c|c|c|c|c|c|c|c|c|c|c|c|c|c|}
\hline & 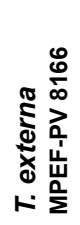 & 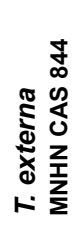 & 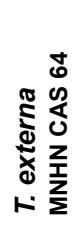 & 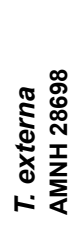 & 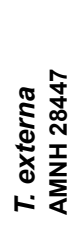 & 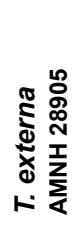 & 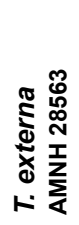 & 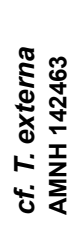 & 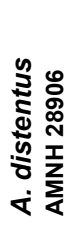 & 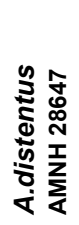 & 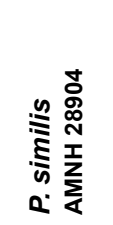 & 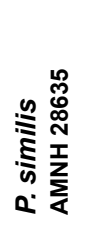 & 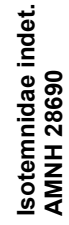 \\
\hline Skull & $x$ & $x$ & & $x$ & & & & & & & M1 only & & \\
\hline Mandible & $x$ & & $x$ & & $x$ & & & & & & & & \\
\hline Scapula & $x$ & & & & & $x$ & & & $x$ & & & & \\
\hline Humerus & $x$ & & & & & $x$ & $x$ & & $x$ & & $x$ & & \\
\hline Ulna & $x$ & & & & & $x$ & $x$ & & $x$ & & $x$ & & \\
\hline Radius & $x$ & & & & & & $x$ & & $x$ & $x$ & $x$ & & \\
\hline Manus & & & & & & & & & $x$ & $x$ & $x$ & & \\
\hline Pelvis & $x$ & & & & & $x$ & & & & & & & \\
\hline Femur & $x$ & & & & & $x$ & & & & & & $x$ & $x$ \\
\hline Tibia & $x$ & & & & & & & & & & $x$ & $x$ & $x$ \\
\hline Pes & $x$ & & & & & & & $x$ & $x$ & & $x$ & & $x$ \\
\hline
\end{tabular}

synonymized with $T$. externa by Simpson, 1967, p. 159

Stratigraphic provenance. MPEF-PV 8166 came from the Cañadón Vaca member of the Sarmiento Formation (Bellosi and Krause, 2014). An age of $\sim 45 \mathrm{Ma}$ has been proposed for the "Vacan" subage (Cifelli, 1985; Carlini et al., 2005; Woodburne et al., 2014). Bellosi and Krause (2014) estimated a range of 43.1-46.9 Ma for the Cañadón Vaca member.

Thomashuxleya systematics. Ameghino (1901) first described Thomashuxleya based on material from the "couches a Notostylops" (now known to be part of the Casamayoran, middle Eocene) and originally assigned it to Homalodotheriidae ("Homalodontotheridae" in Ameghino, 1901). Ameghino designated T. rostrata as the type species (Ameghino, 1901, p. 177). In the same publication, Ameghino recognized three more species within the genus: T. artuata, T. robusta, and T. externa (Ameghino, 1901, p. 179).

Simpson (1967) considered Thomashuxleya to be part of Isotemnidae. Simpson (1967, p. 121) considered five Casamayoran Isotemnidae genera to be valid: Pleurostylodon (Ameghino, 1897), Anisotemnus (Ameghino, 1902), Plexotemnus (Ameghino, 1904a), Isotemnus (Ameghino, 1897), and Thomashuxleya (Ameghino, 1897). For Thomashuxleya, Simpson (1967) recognized two species: T. externa and $T$. rostrata; the latter is recorded in the local fauna south of Colhué Huapí Lake in Gran Barranca, (Barracan; Woodburne et al., 2014a). Other isotemnids present in the fauna of Colhué Huapí are Pleurostylodon modicus and Isotemnus primitivus (Cifelli, 1985).

Shockey and Flynn (2007) studied several of the postcranial elements referred to Thomashuxleya by Simpson $(1936,1967)$, and recognized that at least three genera were included in Simpson's $(1936,1967)$ skeletal reconstruction. Based on the material then available, they inferred a straight posture, plantigrade or semi-digitigrade locomotion, and lack of running among Vacan isotemnids. Of the known Isotemnidae specimens recovered from Cañadón Vaca, MEPF-PV 8166 is the only one with associated craniodental and postcranial elements (Table 2).

\section{Description}

Skull. MPEF-PV 8166 preserves most of the skull, including the cranium with maxillae, palatines, zygomatic arches, nasal, frontal, temporal and occipital, and the almost complete mandible. The skull of MPEF-PV 8166 measures $28 \mathrm{~cm}$ from the most posterior point of the sagittal crest to the most anterior point of the snout. Due to the preservation, the sutures are not visible. In lateral view, the rostrum is high (Figure 2.2). The zygomatic arch is wide and robust, more than in Pleurostylodon (Simpson, 1967). There is a well-defined sagittal crest (Figure 2.2), and the glenoid fossa is wide and concave (Figure 2.1), as in Pleurostylodon (Simpson, 1967). The occipital condyles are oval with a deep intercondylar notch. The paracondylar processes of the exoccipitals are long and narrow. The nuchal crest forms a semicircular outline in 

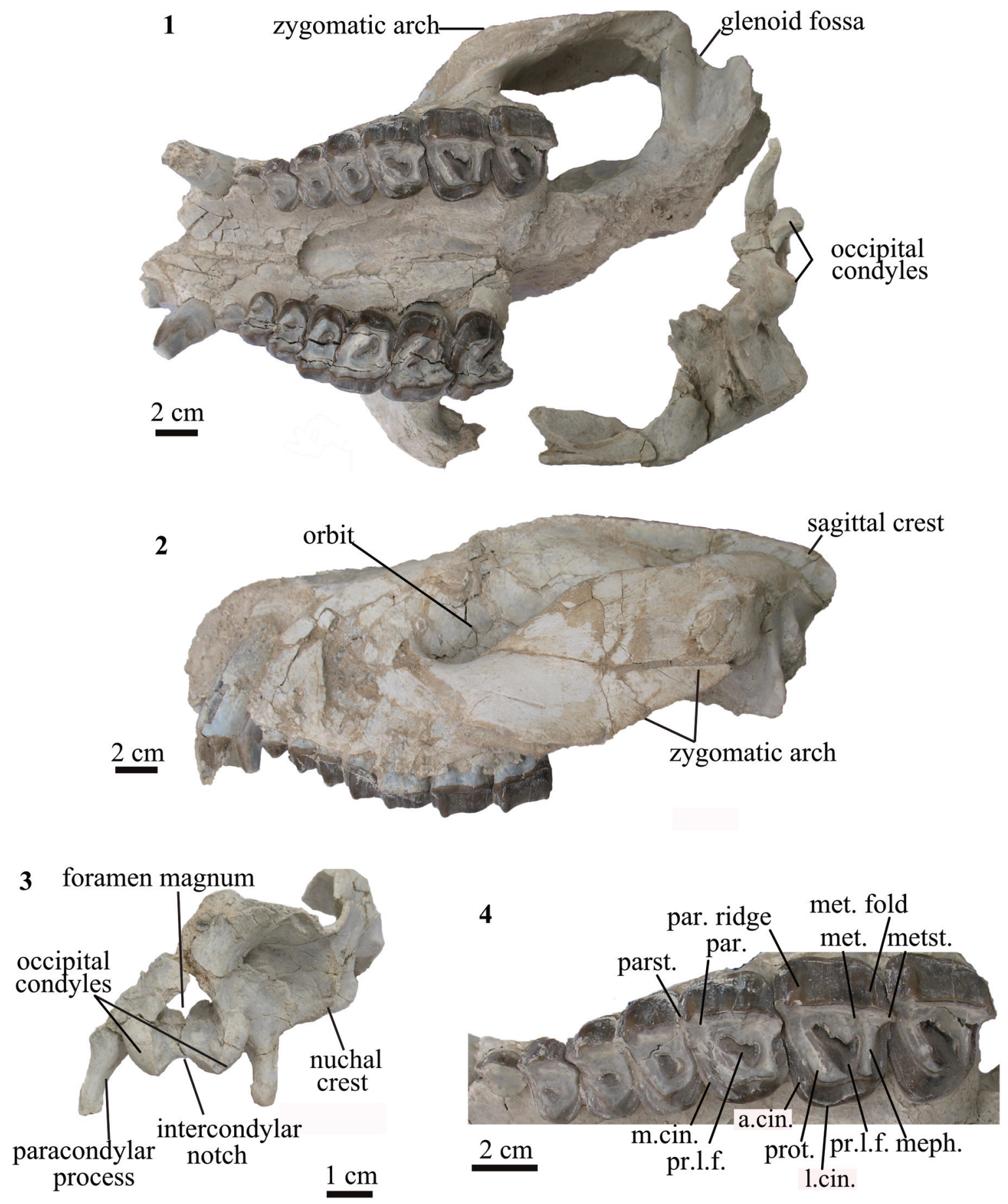

FIGURE 2. Skull of T. externa (MPEF-PV 8166). 1 ventral view; 2 lateral view; 3 occiput in caudal view; 4 detail of upper dentition in occlusal view. Abbreviations are prot=protocone (part of the protoloph), par=paracone (part of the ectoloph), parst=parastyle, met=metacone (part of the ectoloph), metst=metastyle, meph=metaloph, pr.l.f.=primary lingual fold, $\mathrm{m}$. cin=mesial cingulum, I.cin=lingual cingulum. 
posterior view and does not project below the level of the occipital condyles (Figure 2.3). The palate is triangular (Figure 2.2).

Upper dentition. The upper canines are clearly differentiated from the rest of the teeth. The mesiodistal length of each tooth steadily increases from $\mathrm{P} 1$ to $\mathrm{M} 3$ (Figure 2.1). The $\mathrm{P} 1$ is longer than wide, in contrast with Anisotemnus distentus, which has the opposite condition (Simpson, 1967). The P1 is oval in occlusal view and with a single mediolabial cusp (Figure 2.4). It has no mesial or distal stylar projections, in contrast to Pleurostylodon (Simpson, 1967). The P2-P4 are similar, increasing in labio-lingual width from P2 to P4 (Figure 2.4). They have a well-defined paracone ridge, and mesial to it there is a small parastyle, less prominent that in Pleurolystodon (Simpson, 1967). The metacone fold is absent (Figure 2.4). There is a mesial and distal cingulum, as in Pleurolystodon (Simpson, 1967).

The upper molars have a paracone ridge (Figure 2.4) which is less developed than in Pleurostylodon (Simpson, 1967). The metacone fold is observed as a very smooth ridge (Figure 2.4), less defined than in Pleurostylodon and Isotemnus (Simpson, 1967). There is a metastyle, which is more defined in M2 and M3 than in M1 (Figure 2.4). The upper molars have a primary lingual fold surrounded by the protoloph, ectoloph, and metaloph (Figure 2.4). As the teeth wear down, the primary lingual fold closes, forming a fossa (Simpson, 1967), as seen in M1 (Figure 2.4). There is a continuous labial, mesial, and lingual cingula, as in Thomashuxleya (Simpson, 1967). The mesial cingulum surrounds the protocone, reaching the lingual face of the teeth (Figure 2.4), in contrast to Isotemnus, which does not have lingual cingula (Simpson, 1967). The upper molars have no fossettes, which were "numerous and somewhat persistent with wear" in Anisotemnus according to Simpson (1967, p. 136). MPEF-PV 8166 is referred to Thomashuxleya based on the presence of a continuous lingual cingulum in the upper molars and dental dimensions (Simpson, 1967).

In addition of the differences with PleurostyIodon and Isotemnus mentioned above, MPEF-PV 8166 is about $60 \%$ larger than the specimens referred to $P$. similis and about $85 \%$ larger than $I$. primitivus (also recorded in Cañadón Vaca) based on the upper molar dimensions (Table 3; Simpson, 1967, table 45,49,54).

Mandible. The horizontal ramus is straight (Figure 3.2). The vertical ramus is wide and high (Figure 3.2). The masseteric fossa is large and oval (Fig- ure 3.2). The condylar process is wide medio-laterally and narrow rostro-caudally (Figure 3.1). The coronoid process is narrow and high, extending more dorsally than the condylar process (Figure 3.2). The symphysis extends caudally to the level of p3/p4 (Figure 3.1), whereas in Pleurostylodon it extends to the level of p2 (Simpson, 1967). There are two mental foramina in the right horizontal ramus, one at the level of the mesial border of $p 2$ and the other at the level of the mesial border of p3. In Pleurostylodon, the mental foramina are at the level of p3 and p4 (Simpson, 1967).

Lower dentition. The lower dentition has a small diastema of approximately $2 \mathrm{~mm}$ between $\mathrm{p} 1$ and p2. As in the upper teeth, the size increases from $\mathrm{p} 1$ to $\mathrm{m} 3$ (Figure 3.1). The $\mathrm{p} 1$ is triangular in lingual and labial views (Figure 3.2), and it has a median main cusp (Figure 3.3). The p2 has a large protoconid, with a crest projecting mesially, as in Pleurostylodon (Simpson, 1967). The metaconid projects lingually (Figure 3.3) and at its base shows a cingulid (Figure 3.2). The p3 and p4 are bicrescentic in occlusal view and show a high degree of wear. They have a well-defined labial fold (Figure 3.3) and a labial cingulid (Figure 3.2).

The lower molars have well-defined labial and lingual cingulids (Figure 3.2). The talonids are longer mesio-distally than the trigonids (Figure 3.3). The metaconid projects lingually and not distally as in Pleurostylodon (Simpson, 1967). The meta-entoconid fold is mesio-distally long and labio-lingually broad (Figure 3.3). The $\mathrm{m} 3$ has a long talonid, with the entoconid separated from the hypoconulid (Figure 3.3), as in Pleurostylodon (Simpson, 1967). Of the two species currently recognized for Thomashuxleya, we assign MPEF-PV 8166 to T. externa based on the well-defined labial and lingual cingulid (Ameghino, 1901) and its dental dimensions (Table 3; Simpson, 1967).

Scapula. The scapulae of MPEF-PV 8166 differ from AMNH 28905, previously referred to $T$. externa and Anisotemnus distentus (AMNH 28906). The comparison between the two $T$. externa specimens is difficult because MPEF-PV 8166 does not preserve the complete blade, and AMNH 28905 has been modified by post-recovery restoration. When comparing MPEF-PV 8166 with AMNH 28905 as coded by (O'Leary et al., 2013), we observed some differences: the coracoid process is pointing towards the axillary edge of the scapula and not perpendicular to the blade (Figure 4.1-2); the infraspinous fossa does not reach the rim of the glenoid fossa; and it is triangular rather than rectangular in lateral view (Figure 4.3). 
TABLE 3. Dental measurements of Thomashuxleya; * =taken from Simpson (1967).

\begin{tabular}{|c|c|c|c|c|c|c|c|c|c|c|c|c|c|c|c|}
\hline & & \multicolumn{2}{|c|}{ p1 } & \multicolumn{2}{|c|}{ p2 } & \multicolumn{2}{|c|}{ p3 } & \multicolumn{2}{|c|}{ p4 } & \multicolumn{2}{|c|}{ m1 } & \multicolumn{2}{|c|}{ m2 } & \multicolumn{2}{|c|}{ m3 } \\
\hline & & 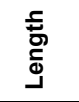 & $\frac{5}{\frac{5}{0}}$ & 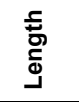 & $\frac{5}{\frac{5}{5}}$ & 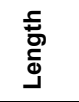 & $\frac{5}{\frac{5}{5}}$ & 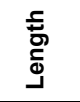 & $\frac{5}{\frac{5}{3}}$ & 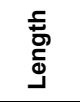 & $\frac{5}{\frac{5}{5}}$ & $\begin{array}{l}\text { 売 } \\
\stackrel{9}{\Phi}\end{array}$ & $\frac{5}{\frac{5}{5}}$ & 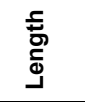 & $\frac{5}{\frac{5}{5}}$ \\
\hline \multirow[t]{8}{*}{ T. rostrata } & MACN 10370* & 13.7 & 11.8 & 17.5 & 12.7 & 18.1 & 14.8 & 20.9 & 16.6 & & & & & & \\
\hline & MACN 10539* & & & & & & & 19.9 & 17.8 & 26 & 19.8 & 26.4 & 19.5 & 37.2 & 16.9 \\
\hline & MACN 10546* & & & & & & & 21.5 & 16.8 & & & & & & \\
\hline & AMNH $28692^{*}$ & & & & & 19.5 & 16.5 & & & 26 & 16.4 & 28.5 & 18.8 & & \\
\hline & AMNH $28764^{*}$ & & & & & & & 21.8 & 13.7 & & & & & & \\
\hline & Mean & 13.7 & 11.8 & 17.5 & 12.7 & 18.8 & 15.7 & 21.0 & 16.2 & 26 & 18.1 & 27.5 & 19.2 & 37.2 & 16.9 \\
\hline & SD & NA & NA & NA & NA & 1.0 & 1.2 & 0.8 & 1.8 & 0.0 & 2.4 & 1.5 & 0.5 & NA & NA \\
\hline & $\mathrm{n}$ & 1 & 1 & 1 & 1 & 2 & 2 & 4 & 4 & 2 & 2 & 2 & 2 & 1 & 1 \\
\hline \multirow[t]{14}{*}{ T. externa } & MACN $10540^{*}$ & & & & & 16.5 & 14.6 & 19 & 17.2 & 21 & & 28 & & 37 & \\
\hline & MACN $10537^{*}$ & & & & & & & 16.3 & 13 & 19.5 & 14 & 23 & 15.5 & & \\
\hline & AMNH $28447^{*}$ & & & 14.2 & 11.1 & 16.2 & 11.6 & 18.1 & 13 & 22.0 & 15.6 & 27.5 & 16.5 & 31.6 & 15.8 \\
\hline & AMNH $28697^{*}$ & & & & & & & 17.3 & 14.2 & 23.2 & 15.9 & 25.5 & 17.2 & 36 & 16.6 \\
\hline & AMNH $28756^{*}$ & & & 14.7 & 10.9 & 15.7 & 12.8 & 16.4 & 14.2 & 21.8 & 16.3 & 25.6 & 17.8 & 32.3 & 16.3 \\
\hline & AMNH $28698^{*}$ & 11.0 & 10.0 & 15.1 & 12.6 & 16.7 & 13.6 & 16.5 & 14.6 & 24 & 16.1 & 26 & 17.8 & 37 & 17 \\
\hline & AMNH 28686* & & & & & & & & & & & & & 34.5 & 17.0 \\
\hline & AMNH $28822^{*}$ & & & & & & & & & 20 & 16.4 & 23 & 18.0 & & \\
\hline & Mean* & 11 & 10 & 14.7 & 11.5 & 16.3 & 13.2 & 17.3 & 14.4 & 21.6 & 15.7 & 25.5 & 17.1 & 34.7 & 16.5 \\
\hline & $\mathrm{SD}^{*}$ & NA & NA & 0.5 & 0.9 & 0.4 & 1.3 & 1.1 & 1.5 & 1.6 & 0.9 & 2.0 & 1.0 & 2.4 & 0.5 \\
\hline & $\mathrm{n}^{*}$ & 1 & 1 & 3 & 3 & 4 & 4 & 6 & 6 & 7 & 6 & 7 & 7 & 6 & 5 \\
\hline & MPEF-PV 8166 & 12.8 & 8.3 & 15.4 & 10 & 16.5 & 10.1 & 16.4 & 13.3 & 20.1 & 15.6 & 22.5 & 15.3 & 32.3 & 15.7 \\
\hline & & \multicolumn{2}{|c|}{ P1 } & \multicolumn{2}{|c|}{ P2 } & \multicolumn{2}{|c|}{ P3 } & \multicolumn{2}{|c|}{ P4 } & \multicolumn{2}{|c|}{ M1 } & \multicolumn{2}{|c|}{ M2 } & \multicolumn{2}{|c|}{ M3 } \\
\hline & & 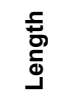 & $\frac{5}{\frac{1}{0}}$ & 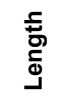 & $\frac{\text { 흔 }}{\frac{1}{3}}$ & 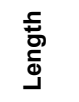 & $\frac{\frac{5}{7}}{\frac{0}{3}}$ & 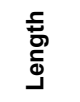 & $\frac{\frac{5}{7}}{\frac{0}{3}}$ & 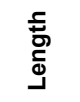 & $\frac{\frac{5}{0}}{\frac{0}{3}}$ & 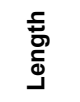 & $\frac{5}{\frac{5}{3}}$ & $\begin{array}{l}\text { 莺 } \\
\text { ఏ) }\end{array}$ & $\frac{5}{\frac{5}{3}}$ \\
\hline \multirow[t]{5}{*}{ T. rostrata } & MACN $10370^{*}$ & 15.4 & 15.7 & 17.0 & 27.2 & 19.5 & 31.2 & 21 & 35 & & & & & & \\
\hline & MACN $10542^{*}$ & & & & & & & & & 29.5 & 41.8 & 33.0 & 44.2 & 28.8 & 40.8 \\
\hline & Mean* & 15.4 & 15.7 & 17 & 27.2 & 19.5 & 31.2 & 21 & 35 & 29.5 & 41.8 & 33 & 44.2 & 28.8 & 40.8 \\
\hline & $S D^{*}$ & NA & NA & NA & NA & NA & NA & NA & NA & NA & NA & NA & NA & NA & NA \\
\hline & $\mathrm{n}^{*}$ & 1 & 1 & 1 & 1 & 1 & 1 & 1 & 1 & 1 & 1 & 1 & 1 & 1 & 1 \\
\hline \multirow[t]{9}{*}{ T. externa } & MACN 10543* & & & & & & & & & 24 & 34 & 28.5 & 35.9 & & \\
\hline & AMNH 28699* & & & 17.5 & 22.1 & 16.8 & 26.4 & 18.5 & 32.1 & 23.8 & 35.8 & 26.7 & 42 & & 39.5 \\
\hline & AMNH $28757^{*}$ & 13.8 & 11.5 & 15.2 & 22.1 & 18 & 26 & & & 25.7 & & 27.2 & 39.2 & & \\
\hline & AMNH 28698* & 10 & 11 & & & 16 & & 18 & 33.2 & 23.9 & 38.7 & 27.2 & 41 & 26 & 41 \\
\hline & MNHN CAS 844 & 10.84 & 13.86 & 17.79 & 22.93 & 18.94 & 26.80 & 19.13 & 31.25 & 21.40 & 32.75 & 22.71 & 35.98 & 26.55 & 35.46 \\
\hline & Mean* & 11.5 & 12.1 & 16.8 & 22.4 & 17.4 & 26.4 & 18.5 & 32.2 & 23.8 & 35.3 & 26.5 & 38.8 & 26.3 & 38.7 \\
\hline & $S D^{*}$ & 2.0 & 1.5 & 1.4 & 0.5 & 1.3 & 0.4 & 0.6 & 1.0 & 1.5 & 2.6 & 2.2 & 2.8 & 0.4 & 2.9 \\
\hline & $\mathrm{n}^{*}$ & 3 & 3 & 3 & 3 & 4 & 3 & 3 & 3 & 5 & 4 & 5 & 5 & 2 & 3 \\
\hline & MPEF-PV 8166 & 10.2 & 10.5 & 14.0 & 16.2 & 15.0 & 21.6 & 14.6 & 25.9 & 25.2 & 31.3 & 27.9 & 36.9 & 24.0 & 32.0 \\
\hline
\end{tabular}




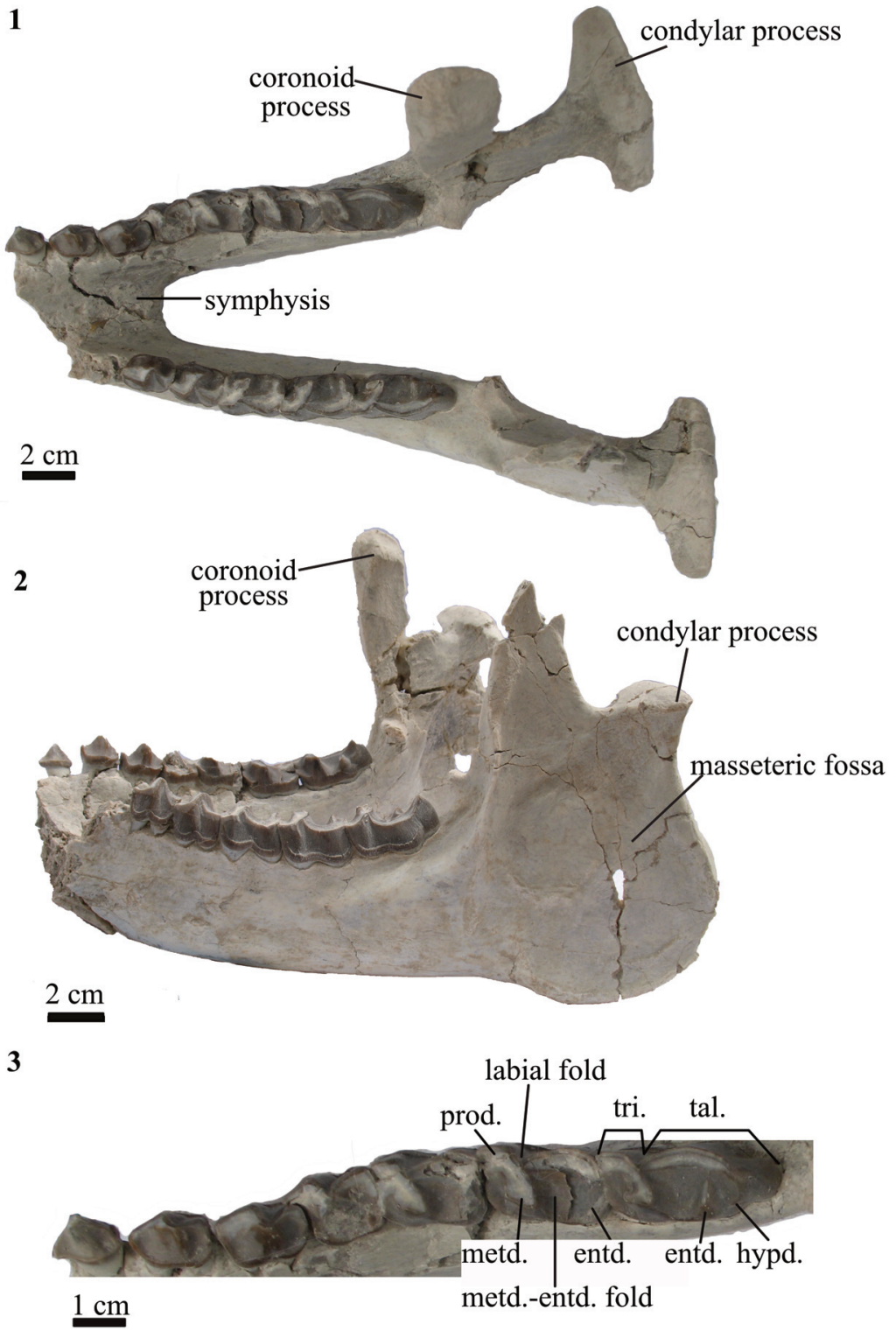

FIGURE 3. Mandible of T. externa (MPEF-PV 8166) in 1 dorsal and 2 lateral views; 3 lower dentition in occlusal view. Abbreviations are tri=trigonid, tal=talonid, prod=protoconid, metd=metaconid, entd=entoconid, hypd=hypoconulid.

In MPEF-PV 8166, the preserved portion of the supraspinous fossa is larger than the infraspinous fossa, as in Anisotemnus (Shockey and Flynn, 2007). The infraspinous fossa narrows proximally towards the glenoid fossa. A narrow portion of the fossa for the teres minor muscle is present. The spine is high, with a lateral projection equal to the medio-lateral width of the glenoid fossa, and narrower than that of Anisotemmnus in lateral view (Figure 4.2-3).

In MPEF-PV 8166 the acromion is not preserved. Thomashuxleya has a well-developed metacromion with quadrangular shape in lateral view; its presence is uncertain in Anisotemnus
(Shockey and Flynn, 2007). The glenoid fossa is circular, as in Anisotemnus, and oriented perpendicular to the main axis of the scapula. In the right scapula of MPEF-PV 8166, the glenoid fossa is taphonomically compressed in the mediolateral plane, resulting in a more oval shape. There is a conspicuous supraglenoid tubercle (Figure 4.1). The coracoid process is well developed and narrower than Anisotemnus, although this could be due to diagenetic compression. The length of the coracoid process is smaller than the maximum diameter of the glenoid fossa. The neck is short and wide, similar to Anisotemnus. 


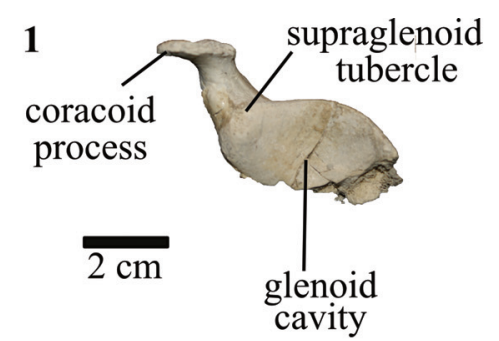

2

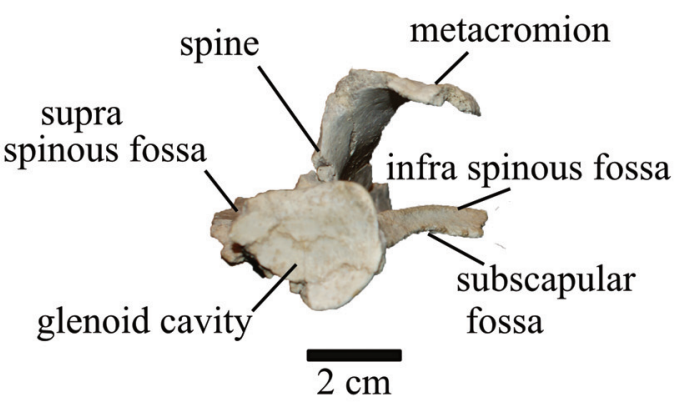

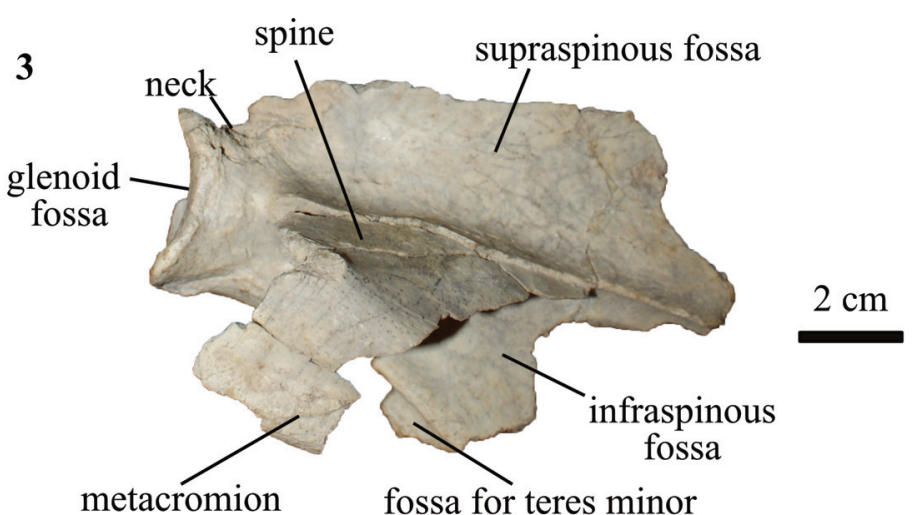

fossa for teres minor

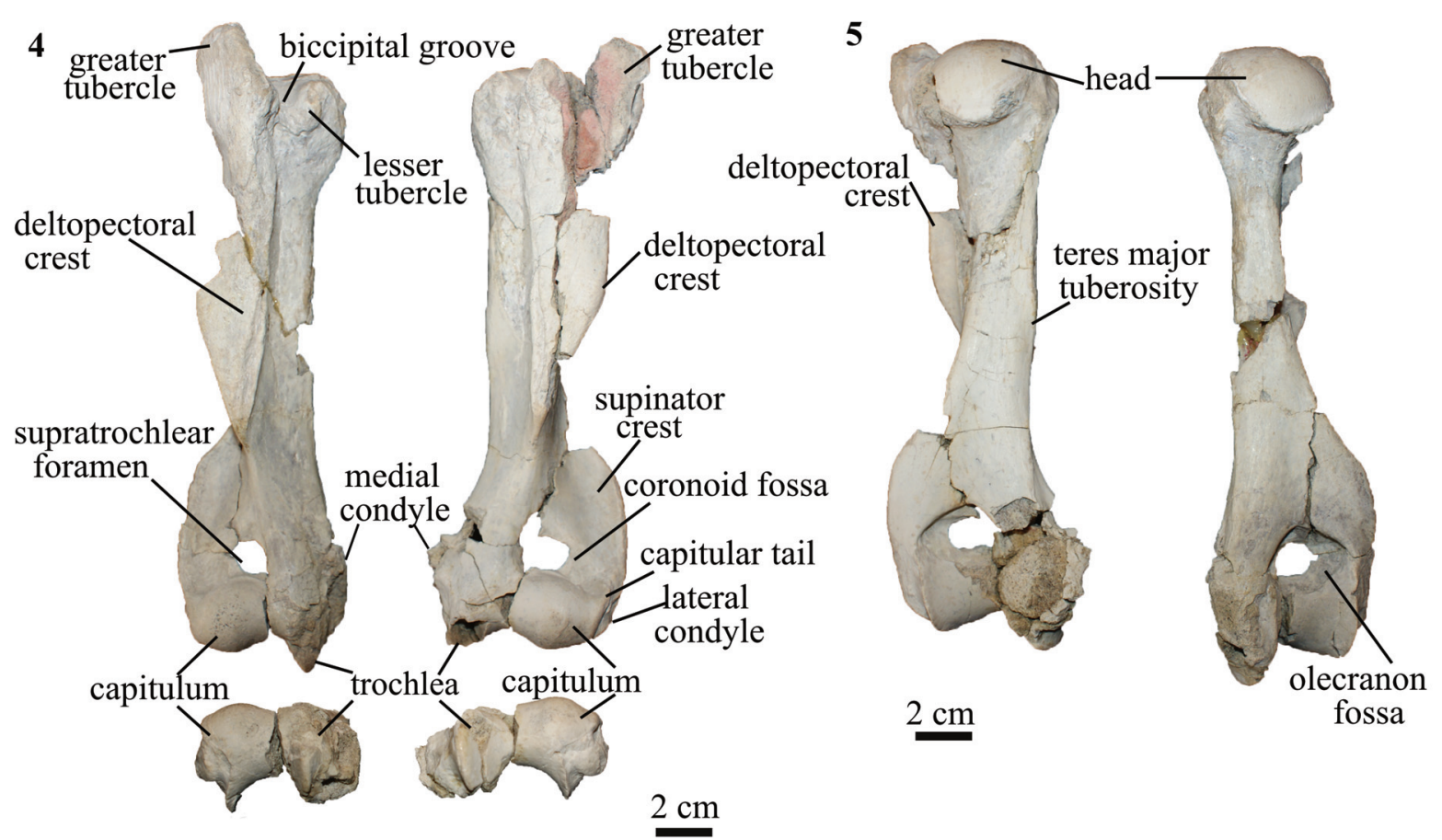

FIGURE 4. Scapulae and humeri of T. externa (MPEF-PV 8166). 1 right and 2 left scapulae in proximal view; 3 left scapula in dorsolateral view; right and left humeri in $\mathbf{4}$ right and left humeri in anterior (top) and distal (bottom) views; 5 right and left humeri in posterior view.

Humerus. In MPEF-PV 8166 both left and right humeri are almost complete (Figure 4.4-4.5). The greater tubercle is high, protruding proximally from the level of the head, as in AMNH 28905. The lesser tubercle is smaller than the greater tubercle and much less developed than in Anisotemnus (Shockey and Flynn, 2007). The bicipital groove is shallow as in Anisotemnus and other specimens of
Thomashuxleya. The articular surface of the head is oriented posteriorly. The anterior margin of the shaft is convex and the posterior one is straight, and the midshaft is triangular in cross-section. The pectoral (medial) and the deltoid (lateral) crest unite to form a deltopectoral crest, which is large, tilts medially towards its distal end, and extends distal to the midshaft, as in Anisotemnus (Shockey 
and Flynn, 2007). On the medial side of the shaft, there is a small Teres major tuberosity, less developed than that of Anisotemnus. The supinator crest is well developed and blade-like as in Anisotemnus and Pleurostylodon.

The capitulum is rounded, similar to Anisotemnus, and is oblique (i.e., directed proximomedially) relative to the proximodistal axis, as in other specimens of Thomashuxleya, and as opposed to the orthogonal orientation in Anisotemnus (Shockey and Flynn, 2007). The medial border of the trochlea is oriented distomedially. The capitulum is wider than the trochlea. The medial crest of the trochlea extends more distally than the capitulum, as in other isotemnids. There is a small, concave capitular tail. The olecranon fossa is shallow (i.e., its depth is less than the maximum diameter of the fossa). The supratrochlear foramen is smaller than the oleocraneon fossa. The presence of the supratrochlear foramen in MPEF-PV 8166 can be assessed with confidence because the borders are preserved. Its presence is uncertain in other Thomashuxleya specimens (O'Leary et al., 2013), and it is absent in Pleurostylodon and likely absent in Anisotemnus (Shockey and Flynn, 2007). The medial condyle is not well preserved, and is not possible to assess the presence of an entepicondylar foramen, which is otherwise present in other Thomashuxleya specimens, Anisotemnus and Pleurostylodon. The lateral condyle is located more distally than the medial condyle, and there is a distinct radial fossa.

Differences between the humeri of MPEF-PV 8166 and AMNH 28905 (O'Leary et al., 2013) are as follows: in MPEF-PV 8166 the bicipital groove is narrower; the lateral condyle (ectepicondyle) is lateral and not proximal to the capitulum; the coronoid fossa is perforated by the supratrocheal foramen; and the anterior border of the trochlea does not project beyond the plane of the anterior border of the shaft.

Ulna. The right and left ulnae are almost complete except for the most distal portion on the left and the incomplete styloid process on the right (Figure 5.1). The shaft is straight. When articulated, the ulna extends distally as long as the radius. Similar to Anisotemnus (AMNH 28906), the shaft does not taper distally and is strongly excavated in the lateral side. In Pleurostylodon (AMNH 28904), the lateral margin is less excavated. In lateral view, the shaft is straight along its whole length and not anteriorly concave as observed in other Thomashuxleya specimens (e.g., AMNH 28653; Shockey and Flynn, 2007).

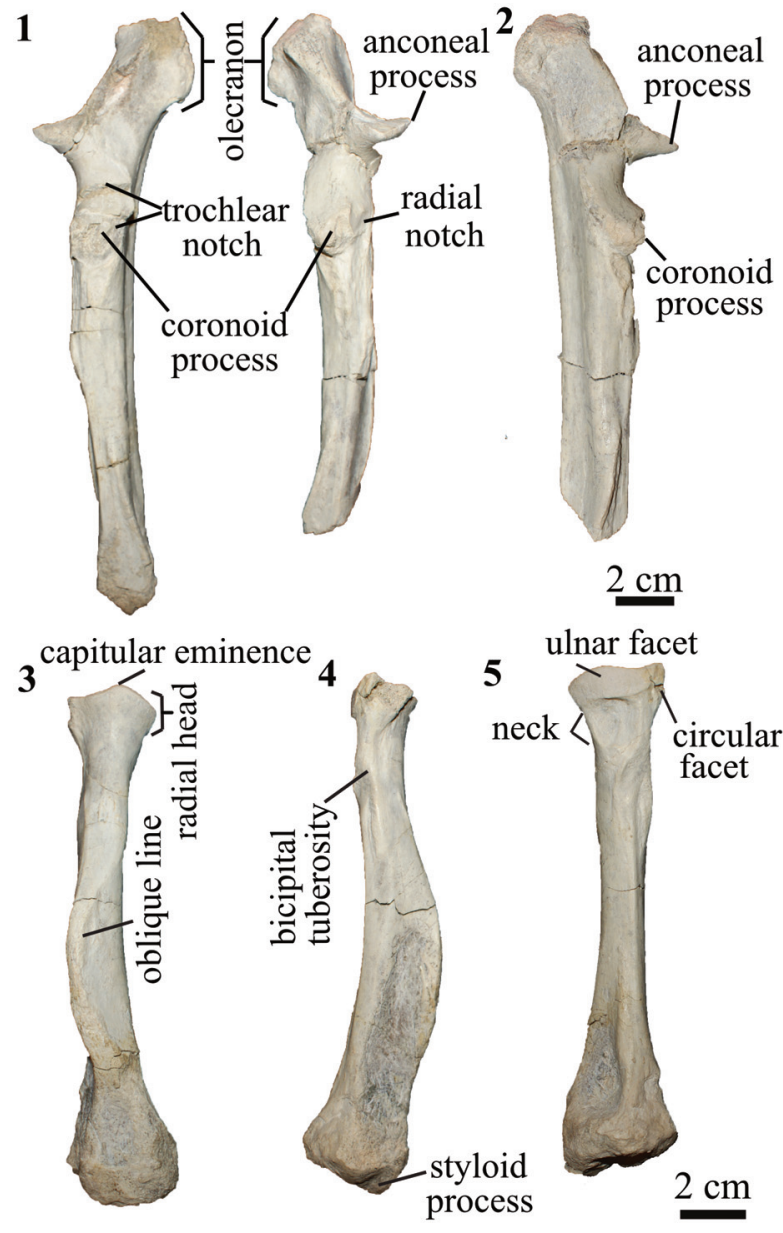

FIGURE 5. Forelimb of T. externa (MPEF-PV 8166). 1 right and left ulnae in frontal view; 2 left ulna in medial view; right radius in $\mathbf{3}$ frontal, $\mathbf{4}$ lateral, and $\mathbf{5}$ posterior views.

The olecranon process of the ulna is long (longer than the trochlear notch) and tilts medially as in Anisotemnus and as opposed to Pleurostylodon, where it is straight (Shockey and Flynn, 2007). In lateral view, the olecranon extends posterior to the level of the shaft, in contrast with Anisotemnus and Pleurostylodon, where it is more aligned with the shaft (Shockey and Flynn, 2007). The trochlear notch forms a crescent in lateral view and is wider than the midshaft. The coronoid process is as large as the radial notch, in contrast with the larger radial notch in Anisotemnus (Shockey and Flynn, 2007). The anconeal process extents laterally and anteriorly (more anterior than the coronoid process), and its width represents about $63 \%$ of that of the trochlear notch (Table 4).

The ulnae of MPEF-PV 8166 differ from AMNH 28905 (O'Leary et al., 2013) in the following characters: the absence of a ridge on the lateral 
TABLE 4. Postcranial measurements of MPEF-PV 8166. * Translated from Spanish in Elissamburu (2012).

\begin{tabular}{|c|c|c|c|c|}
\hline & \multicolumn{2}{|c|}{ Value (mm) } & \multicolumn{2}{|c|}{ Acronym } \\
\hline & Left & Rigth & Scott (1990) & Elissamburu (2012) \\
\hline \multicolumn{5}{|l|}{ Scapula } \\
\hline Height of the spine & 31.0 & 31.4 & & \\
\hline \multicolumn{5}{|l|}{ Humerus } \\
\hline Humerus functional length* & 193 & 204 & $\mathrm{H} 1$ & LFH \\
\hline Humerus trochlear diameter ${ }^{*}$ & 52.0 & 43.3 & $\mathrm{H} 4$ & DtrH \\
\hline Maximum length & 211 & 210 & & \\
\hline Maximum diameter of the head & 44.0 & 40.5 & & \\
\hline Maximum diameter of the mayor tuberosity & & 46.6 & & \\
\hline Maximum diameter of the minor tuberosity & & 16.6 & & \\
\hline Maximum widht of the trochlea & 30 & & & \\
\hline \multicolumn{5}{|l|}{ Radius } \\
\hline Maximum length & 155 & 153 & & \\
\hline Maximum mediolateral width of the medial shaft & 14.1 & 14.0 & & \\
\hline Maximum diameter of the head & 32.0 & & & \\
\hline Minimum diameter of the head & 20.3 & 20.4 & & \\
\hline Maximum diameter of the neck & 20.3 & 19.5 & & \\
\hline Mediolateral width of the distal epiphysis & & 36.0 & & \\
\hline $\begin{array}{l}\text { Diameter perpendicular to the maximum width of the } \\
\text { distal epiphysis }\end{array}$ & & 31.6 & & \\
\hline \multicolumn{5}{|l|}{ Ulna } \\
\hline Anteroposterior diameter of the diaphysis & 28.3 & 28.1 & & \\
\hline Olecraneum height & 64.9 & 63.7 & & \\
\hline Anteroposterior diameter of the oleocranon & 32.6 & & & \\
\hline Proximo-distal length of the trochlear notch & 35.9 & & & \\
\hline Trochlear notch width & & 32.6 & & \\
\hline Width of anconeal process & & 20.5 & & \\
\hline \multicolumn{5}{|l|}{ Femur } \\
\hline Anteroposterior diameter of the shaft & & 25.5 & $\mathrm{~F} 7$ & DAPF \\
\hline Mediolateral diameter of the shaft & & 36.2 & F6 & DTF \\
\hline \multicolumn{5}{|l|}{ Tibia } \\
\hline Mediolateral diameter of proximal epiphysis & & 55.0 & T2 & DTpT \\
\hline Anteroposterior diameter of proximal epiphysis & & 44.8 & & \\
\hline Lateral condyle transverse width & & 28.0 & & \\
\hline Lateral condyle anteroposterior width & & 25.0 & & \\
\hline \multicolumn{5}{|l|}{ Astragalus } \\
\hline Transverse width of tibial trochlea & 27.7 & & Li 1 & \\
\hline Minimum width of the neck & 14.8 & & & \\
\hline Width sustentacular facet & 17.4 & & & \\
\hline \multicolumn{5}{|l|}{ Navicular } \\
\hline "Dorsal-plantar" width & & 25.6 & & \\
\hline Astragalar facet transverse width & & 24.0 & & \\
\hline Astragalar facet dorsoventral depth & & 25.0 & & \\
\hline \multicolumn{5}{|l|}{ Pelvis } \\
\hline Maximum width of the ilium, above the acetabulum & & 42.3 & & \\
\hline
\end{tabular}


side of the olecranon, the medial inclination of the olecranon, and the absence of a tuberosity on the anterior surface distal to the trochlear notch.

Radius. The radius is approximately $70 \%$ the length of the ulna (Table 4). The anterior margin of the shaft is convex in lateral view (Figure 5.4) and widens distally, as in Anisotemnus and Pleurostylodon. The midshaft is oval in cross-section. The head is oval in proximal view. There is a conspicuous capitular eminence, more developed than in Pleurostylodon, but less than in Anisotemnus (Shockey and Flynn, 2007). The bicipital tuberosity is small and placed below an enlarged fossa (Figure 5.4). The ulnar facet is broad and convex (Figure 5.5). There is a circular facet lateral to the ulnar facet as in Anisotemnus. It articulates with the radial notch of the ulna, and it does not seem to be a facet for an elbow sesamoid, as observed in Nesodon (Scott, 1912) or Adinotherium (Croft et al., 2004). The styloid process is short and projects distally, and there is a conspicuous oblique line on the anterior margin (Figure 5.3-5.4). The distal epiphysis is wider than the shaft, and the main axis of the distal articular surface is posterolateral to anteromedial in distal view. In the left radius, the distal epiphysis was diagenetically compressed in the anteroposterior axis.

The radii of MPEF-PV 8166 differ from AMNH 28905 (O'Leary et al., 2013) in having a proximolateral radial facet, an oval rather than round midshaft cross-section, the presence of an anterior oblique line, and a wide distal epiphysis (but not more than twice as wide as the shaft).

Pelvis. Among isotemnids, the pelvis is only known for Thomashuxleya (Simpson, 1936, 1967). In MPEF-PV 8166 the pelvis preserves portions of the right ilium and ischium, but not the pubis (Figure 6.1-6.2). The anterior process of ilium is mediolaterally broad and elongated (Figure 6.1) as in AMNH 28905 (Simpson, 1936; O'Leary et al., 2013); in lateral view (Figure 6.2), the ilium is straight and thin. The acetabulum is circular and oriented posterolaterally. The ischium is in the same anterodorsal plane that the ilium, and projects dorsally from the acetabulum. The posterior part of the ischium is missing.

Femur. In both femora, the proximal and distal epiphyses are missing and only the shaft and isolated head are preserved (Figure 6.3). Limb suture closure sequence is highly variable in mammals, and several placentals show incomplete fusion of growth plates in adulthood (Geiger et al., 2014). Bone histology from femoral cross-section indicates the specimen was skeletally mature (see below). This suggests that Thomashuxleya had unfused femoral epiphyses into adulthood, as seen in some other mammals (Geiger et al., 2014). The head is spherical with a fovea capitis, enclosed in the articular surface. The trochanteric fossa is deep; the lesser trochanter is smaller than that of AMNH 28905 (O'Leary et al., 2013) and the third trochanter is conspicuous. In lateral view, the anterior border of the shaft is curved and the posterior border is concave.

Tibia. In Thomashuxleya (MPEF-PV 8166) the tibia and fibula are not fused. In proximal view, the mediolateral width of the proximal epiphysis is greater than the anteroposterior depth, the tibial tuberosity is robust and there are no signs for intercondylar eminences (Figure 6.4). The lateral condyle is circular there is a shallow fossa. The cross section at midshaft is crescent-like, with a lateral concavity. The postero-medial portion of the distal epiphysis of the tibia is not preserved. The distal articulation surface of the tibia with the fibula is small and visible in distal view (Figure 6.4). In other isotenmids, a partial tibia is only known for an indeterminate isotemnid (AMNH 28690) and PleurostyIodon (AMNH 28904) (Shockey and Flynn, 2007; Simpson, 1936, 1967).

Astragalus. The astragalus of MPEF-PV 8166 is the first isotemnid found in association with dental remains that corroborates its species-level identification. It is a left astragalus missing the posteriormost portion of the body (Figure 6.5-6). The astragalus of MPEF-PV 8166 is similar in the overall morphology of AMNH 142463, which, based on its size, was referred to cf. Thomashuxleya externa by Shockey and Flynn (2007) (Table 5).

In MPEF-PV 8166 the body is broad and short, as in AMNH 142463. It has a relative shorter neck in comparison with the elements referred to Thomashuxleya rostrata, Pleurostylodon modicus, and other isotemnid specimens (Ameghino, 1904b: figures 24, 28-30). The presence of an enlarged medial plantar tuberosity ("medial process" in Shockey and Flynn, 2007; "anterior medial plantar tuberosity" in Szalay, 1994) could not be confirmed as the structure is broken. The trochlear groove is shallow, and the lateral and medial borders of the trochlea are at the same height, in contrast to AMNH 142463 and AMNH 28690 (Isotemnidae indet.) where the lateral border is slightly higher than the medial (Shockey and Flynn, 2007). The trochlea is wider relative to the astragalar length in MPEF-PV 8166 than in AMNH 142463 and the plane of the articulation surface of the lateral facet is almost perpendicular to the trochlear width. The 


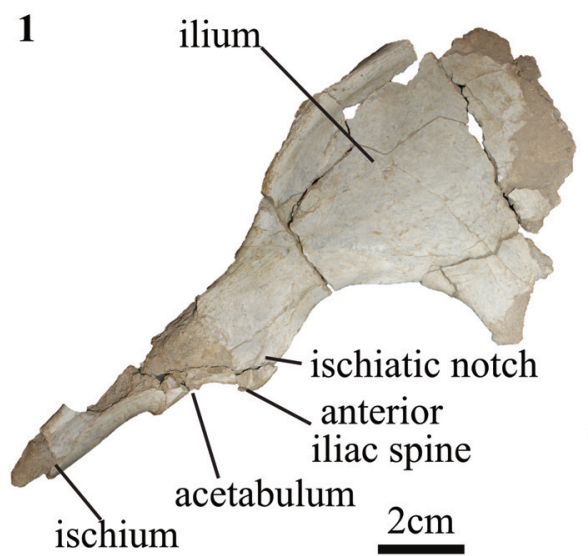

4

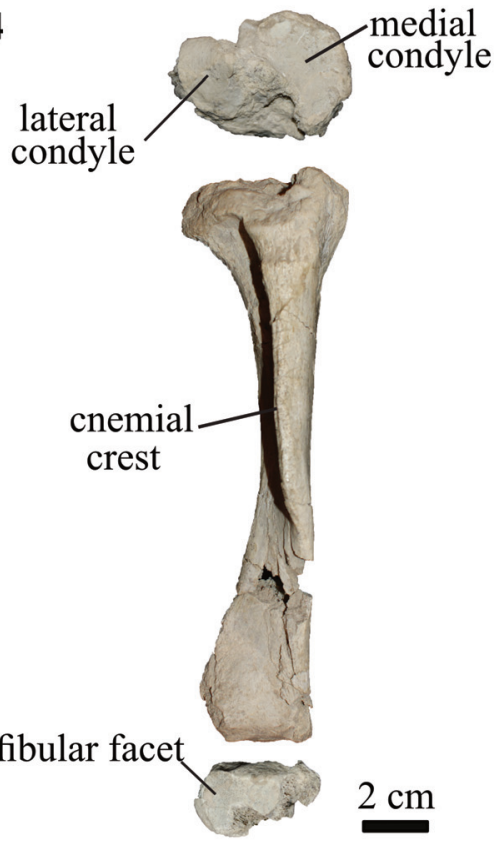

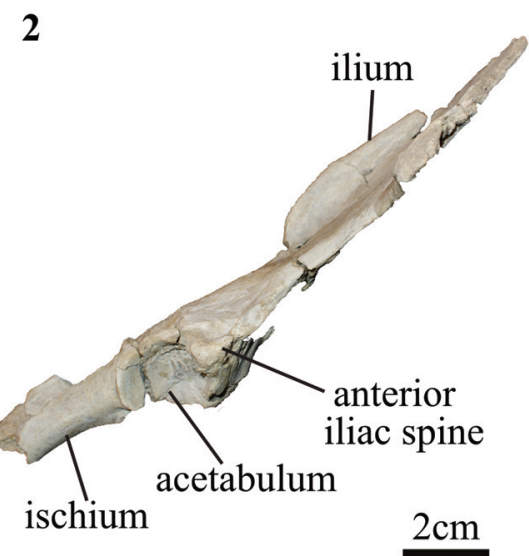

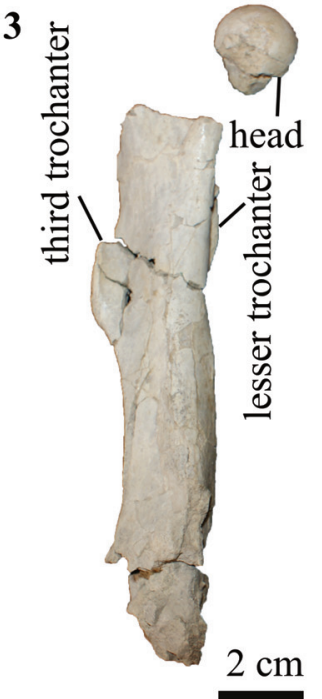

5

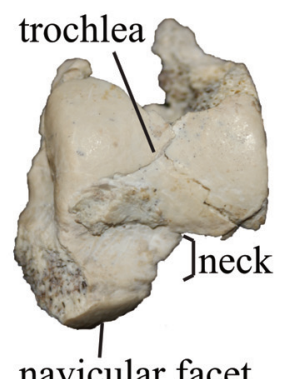

6

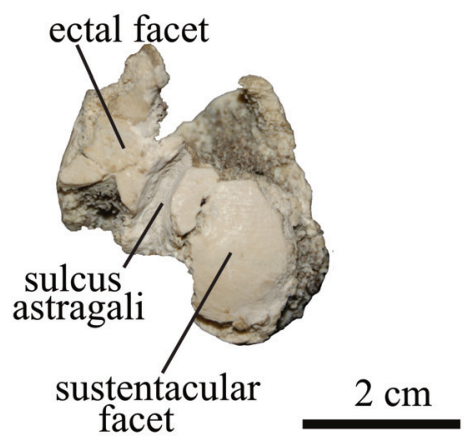

7

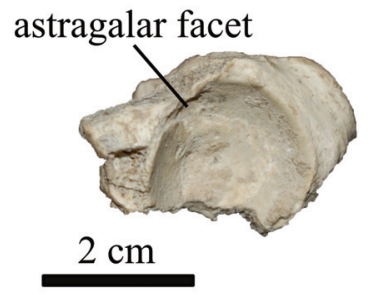

8 navicular medial

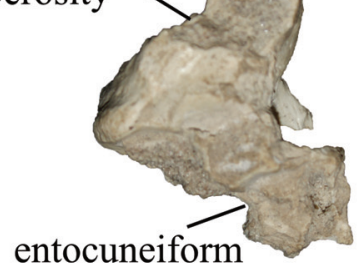
tuberosity

FIGURE 6. Hindlimb of T. externa (MPEF-PV 8166). right pelvis in 1 dorsal and 2 lateral views; $\mathbf{3}$ right femur in anterior view; 4 right tibia in proximal (top), anterior (middle) and distal (bottom) views; left astragalus in $\mathbf{5}$ dorsal and $\mathbf{6}$ plantar views; $\mathbf{7}$ right navicular in proximal view; 8 navicular and entocuneiform in plantar views.

neck is short (Figure 6.5). In dorsal view, the neck represents about half of the trochlear width, similar to AMNH 142463. The navicular facet is convex and anteromedial to the facets for the tibia (Figure 6.5).

The sustentacular facet is elongated anteroposteriorly and covers about half of the astragalus plantar width (Figure 6.6). The proximomedial portion of the sustentacular and the proximal and distal edges of the ectal facets are broken; a welldefined sulcus astragali separates the two. The ectal facet is restricted to the plantar plane. In ventral view, the medial portion of the navicular facet extends proximally and almost contacts the sustentacular facet (Figure 6.6). There is no cotylar fossa, and the medial astragalar facet is thin and constricted to the medial edge of the trochlea. In MPEF-PV 8166 the most posterior portion of the astragalar body is broken and therefore uninformative regarding the presence of an astragalar foramen, as described for AMNH 142463 and AMNH 
TABLE 5. Isotemnid astragali measurements in $\mathrm{mm}$.

\begin{tabular}{llcccc}
\hline \multicolumn{1}{c}{ Specimen No. } & \multicolumn{1}{c}{ Locality } & $\begin{array}{c}\text { Maximum } \\
\text { length }\end{array}$ & $\begin{array}{c}\text { Trochlear } \\
\text { width }\end{array}$ & $\begin{array}{c}\text { Maximum } \\
\text { width }\end{array}$ & Head width \\
\hline MPEF-PV 8166 & Cañadón Vaca & & 27.7 & & \\
AMNH 142463 & Cañadón Vaca & & 35.9 & 41.4 & 17.7 \\
AMNH FM 14501 & "Notostylops beds" & 32.8 & 21.8 & 32.1 & 20.6 \\
AMNH 28690 & Cañadón Vaca & 22 & 12 & 16.7 & 9.3 \\
AMNH 142464 & Cañadón Vaca & 20.5 & 8.9 & \\
\hline
\end{tabular}

28690 (Simpson, 1936, 1967; Shockey and Flynn, 2007).

Navicular. MPEF-PV 8166 preserves a right navicular articulated with a fragment of the entocuneiform (Figure 6.7-8). The astragalar facet is circular and deeply concave as described for Pleurostylodon (AMNH 28904) and an indeterminate isotemnid (AMNH 28690; Shockey and Flynn, 2007). The plantar process is present and elongated, with a rounded end. The navicular medial tuberosity is high and conspicuous as in Colbertia, Allalmeia (Lorente et al., 2014), and AMNH 28690 (Shockey and Flynn, 2007). The cuboid facet is oblique and faces distolaterally, suggesting that the cuboid extended more distally than the navicular. Thomashuxleya seems to have the reverse alternate tarsus condition in which the "astragolocuboid contact is lost and calcaneonavicular contact is achieved," following Cifelli (1993, p. 206), although it is not possible to determine if there was a calcanealnavicular contact as the proximal border is broken.

Metapodials and phalanges. There is a complete first metapodial, which is long, narrow, and flat. The condyles are asymmetrical, with the lateral one more projected distally than the medial one. The lateral border is concave, and the medial one convex. The proximal epiphysis has a triangular shape and is wide transversally.

Three intermediate phalanges are complete, short, and wide. Two of them are symmetrical, and the remaining phalanx is smaller and asymmetrical. In addition, two ungual phalanges were recovered.

\section{Body Mass Estimates}

We recovered a wide range of body mass estimates depending on the equation used. The widest range of body mass estimates were obtained with dental measurements (Appendix 1). The second upper molar width gives the highest body mass estimation $(1501 \pm 583.8 \mathrm{~kg})$, and the second lower molar length gives the lowest $(289 \pm$ $92.2 \mathrm{~kg}$ ). Among craniomandibular measurements the posterior jaw length yielded the lowest estimate
(26 $\pm 9.5 \mathrm{~kg}$ ), and the maximum width of the mandibular angle yielded the highest $(209 \pm 84.6 \mathrm{~kg})$. Regression equations based on postcranial measurements also show considerable variation, but not as much: the highest value is given by the anteroposterior diameter of the femur (304 \pm 69.9 $\mathrm{kg}$ ) and the lowest by the transverse diameter of the tibia's proximal epiphysis $(72 \pm 15.1 \mathrm{~kg})$. The astragalus yielded an estimate of $84 \pm 24.2 \mathrm{~kg}$. The arithmetic mean and standard deviation of all the measurements combined were $354.8 \mathrm{~kg}$ and 356.2 $\mathrm{kg}$, respectively. The body mass estimations of all the 19 variables analysed have a geometric mean of $235.9 \mathrm{~kg}$ and after the bootstrap the $95 \%$ confidence interval ranges between $158.1 \mathrm{~kg}$ and 354.7 $\mathrm{kg}$. The median is $304 \mathrm{~kg}$, the mode $396 \mathrm{~kg}$, and the kurtosis (a descriptor of the tails of the distribution), is 2.97. As shown in Appendix 1, craniomandibular variables gave a mean of $126 \mathrm{~kg}$ and standard deviation of $92.7 \mathrm{~kg}$; dental variables yielded (respectively) $556.4 \mathrm{~kg}$ and $390.3 \mathrm{~kg}$; limbs yielded $143.2 \mathrm{~kg}$ and $92.9 \mathrm{~kg}$. The estimates using multivariate regression equations yielded a mean of $180.5 \mathrm{~kg}$ and a standard deviation of $4.9 \mathrm{~kg}$ (Appendix 2).

\section{Bone Histology}

The cross-section shows some sediment in the medullary cavity (Figure 7.1) but can nonetheless be interpreted and represented schematically. Thomashuxleya femora display a large open medullary cavity surrounded by the cortex (Figure 7.2), which is not particularly thick in comparison with other large SANUs (Houssaye et al., 2016, figure 3 ). The image does not allow assessment of the relative thickness of the spongious transition zone.

Secondary bone of large mammals is typically represented by dense Harvesian bone (Kolb et al., 2015b). The bone sample of Thomashuxleya is characterized by a compact cortex and a spongiosa medullary cavity (Figure 7.1). The sample shows strong remodelling resulting in dense Haversian bone in the inner cortex (Figure 7.3-4). The primary fibrolamellar bone shows strong laminar 

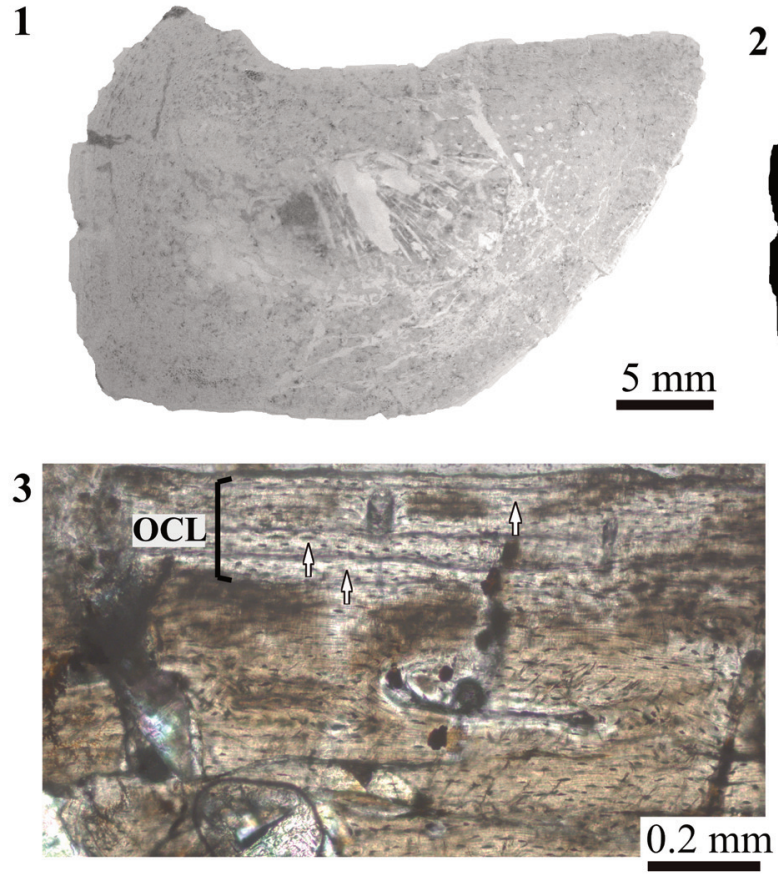
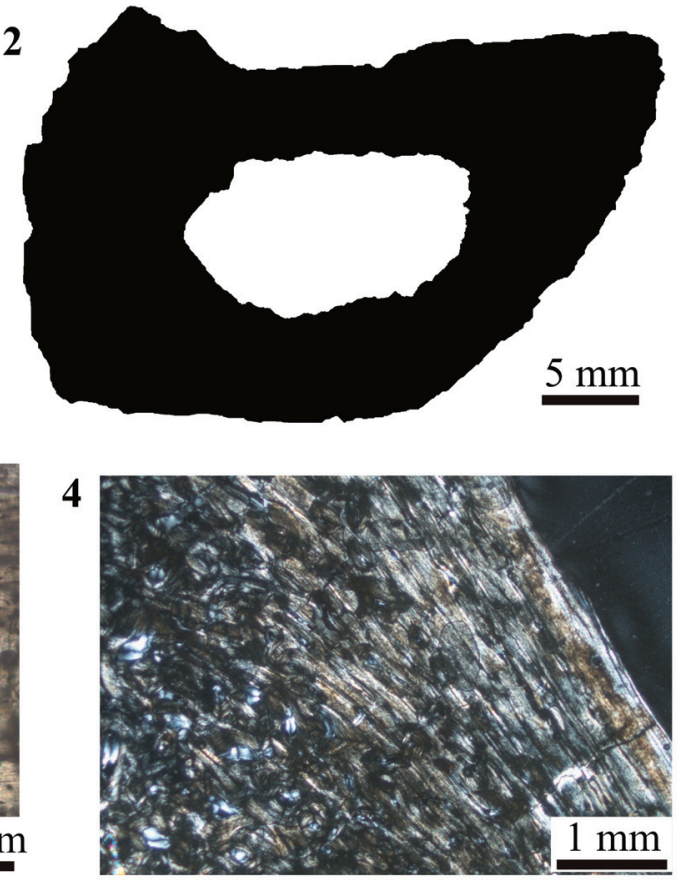

FIGURE 7. Bone histology and microstructure of T. externa (MPEF-PV 8166). 1 Cross section of the midshaft of the right femur; 2 same as 1 after conversion to a binary image (black represents bone and white the cavities); 3 bone histology under linear polarized light, with black arrows pointing the lines of arrested growth (LAGs). OCL= Outer circumferential layer. 4 Bone histology under cross polarized light.

and longitudinal vascularization. Towards the medullary region, resorption cavities are large and common. An outer circumferential layer (OCL) (Ponton et al., 2004) consisting of avascular lamellar bone is present. The OCL indicates that, despite incompletely fused femoral epiphyses, the specimen reached skeletal maturity (Kolb et al., 2015a; Martinez-Maza et al., 2014). A minimum of three lines of arrested growth (LAGs) could be identified within the OCL (Figure 7.3).

\section{Phylogenetic Analysis}

Relationships of Thomashuxleya within Notoungulata. The new Thomashuxleya specimen (MEPF-PV 866) provided information to code seven craniodental character states previously unknown for the genus in the character matrix of Deraco and García-López (2015) (see characters [and states] in Morphobank project 2084, 34[1], 35[0], 56[1], 83[0], 96[0], 97[0], 101[0]). The parsimony analysis yielded 281 trees, 420 steps long, with a consistency index $(\mathrm{Cl})$ of 0.383 and retention index (RI) of 0.765. A strict consensus of these trees (Figure 8) shows the same topology as that obtained by Deraco and García-López (2015; figure 5), with Notoungulata showing a basal polytomy including Henricosbornia, Simpsonotus,
Pampatemnus deuteros, Notostylopidae (including Pyrotherium), Toxodontia and Typotheria. The synapomorphies of the main clades within Notoungulata and Toxodontia are the same as listed by Deraco and García-López (2015; figure 5), and therefore they are not repeated here.

Within Toxodontia, Pampatemnus infernalis appears as the most basal taxon. The sister clade shows a polytomy including Pleurostylodon, a (Ryphodon [Thomashuxleya, Periphragnis]) clade, and another consisting of the remaining members of Toxodontia (Figure 8). The synapomorphies supporting the clade (Ryphodon [Thomashuxleya, Periphragnis]) are also the same as listed by Deraco and García-López (2015; figure 5). Thomashuxleya has two autapomorphies: the posterolabial fossette on the upper molars disappearing before the closure of the central fossette (34[1]), and the mandibular foramen located at the level of the alveolar border (139[1]).

Relationships of Thomashuxleya within placentals. We applied parsimony (MP) using TNT to the combined morphology and protein dataset, including collagens recovered from extant species and Pleistocene fossils (Welker et al., 2015), amino acids for extant taxa (Meredith et al., 2011), and morphology for extinct and extant taxa (O'Leary et 


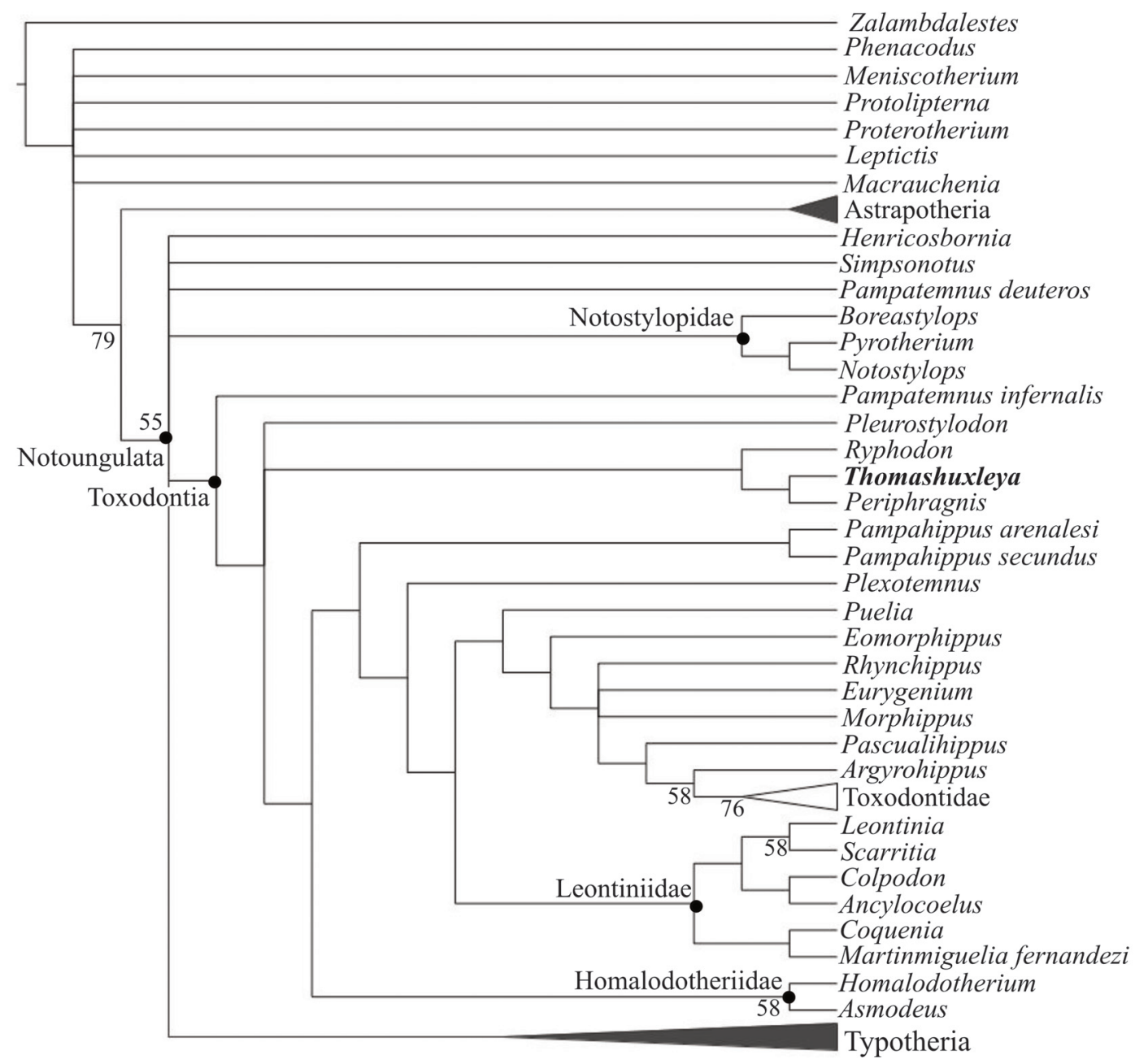

FIGURE 8. Strict consensus of 281 trees, 420 steps in length showing the phylogenetic relationships of Thomashuxleya within Notoungulata based on the morphological dataset of Deraco and García-López (2015). Numbers indicate bootstrap values above 50 .

al., 2013) including our revised anatomical characters for Thomashuxleya. This recovered the basic structure of the now well-corroborated tree of placental mammals (Murphy et al., 2001; Tarver et al., 2016). MP analysis with the extended implied weighting yielded 510 trees, 122374 steps long, with a consistency index $(\mathrm{Cl})$ of 0.345 and retention index (RI) of 0.638. A strict consensus of these trees (Figure 9) divides meridiungulates between Afrotheria and Laurasiatheria. Thomashuxleya and Carodnia (sampled for morphology only) are within Afrotheria as sister taxa of tethytheres (i.e., Proboscidea and Sirenia), with a bootstrap value of 10 and 69, respectively. Toxodon and Macrauchenia (sampled for collagen sequences from Welker et al., 2015) are in a polytomy among perissodactyls, including Mesohippus and the fossil Equus sp. with a bootstrap value of 56. Protolipterna and Didolodus appear in the same clade with Hyopsodus and Phenacodus, as early divergent members of Euungulata (i.e., perissodactyls and artiodactyls), with a bootstrap value of 88 .

We then constrained MP to support the monophyly of each of two clades (but not the two clades together): Notoungulata (Toxodon and Thomashuxleya) and Litopterna (Macrauchenia and Protolipterna). This yielded 620 trees of 122391 steps, with a $\mathrm{Cl}$ of 0.345 and $\mathrm{RI}$ of 0.638 . In the strict consensus, Carodnia is within Afrotheria as sister taxa to tethytheres. The remaining SANUs form a clade with Hyopsodus and Phenacodus, as sister taxon to Euungulata (Figure 10). The Wilcoxon ranks test shows that there is not a significant difference ( $p$ value > 0.05; Table 6 ) between the Notoungulata 


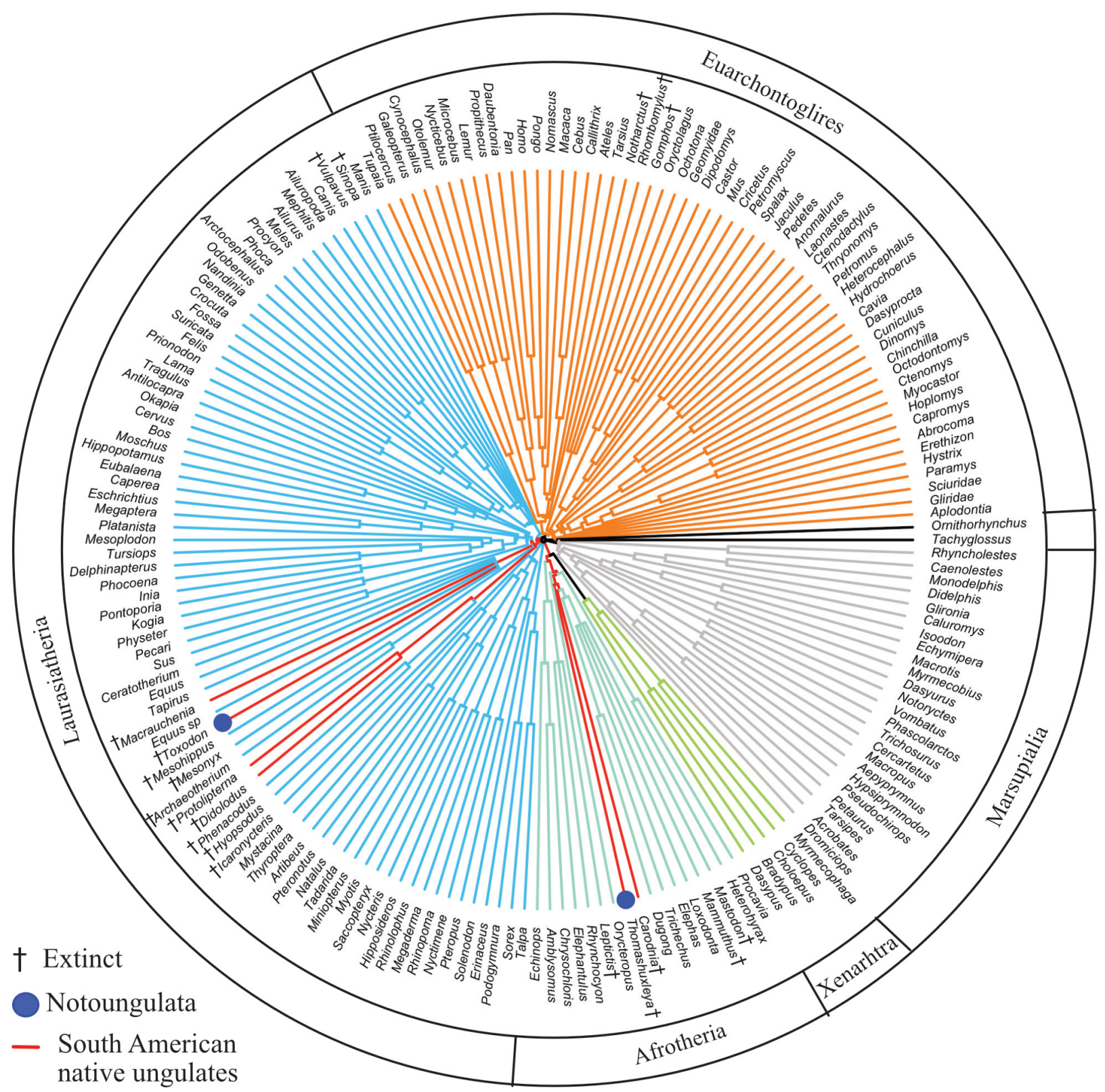

FIGURE 9. Strict consensus of 510 trees, 122374 steps in length from unconstrained parsimony analysis of combined proteomic and morphological data.

and Litopterna constraint and the globally optimal topology.

In order to test the different hypothesis regarding the relationships of SANUs, we also constrained all SANUs to form a clade (Meridiungulata). This hypothesis was proposed by McKenna (1975) based on biogeography, but it has not received support by the morphological data (e.g., Horovitz, 2004; Muizon and Cifelli, 2000). The "Meridungulata" constraint yielded 340 trees of 122424 steps, with a Cl of 0.345 and RI 0.638 . The strict consensus results in a polytomy with all
SANUs plus Hyopsodus and Phenacodus forming the sister taxon of Euungulata. Again, a Wilcoxon rank sum test indicates there is not a significant difference ( $p$ value > 0.05; Table 6 ) between the "Meridiungulata" constraint and the globally optimal topology.

The unconstrained Bayesian analysis yielded an average standard deviation of split frequencies (SDSF) of 0.010 after $3,000,000$ generations. This value is well under the recommended SDSF value of 0.05 (Ronquist et al., 2011); however, a number of other metrics identified in Tracer (Rambaut et 


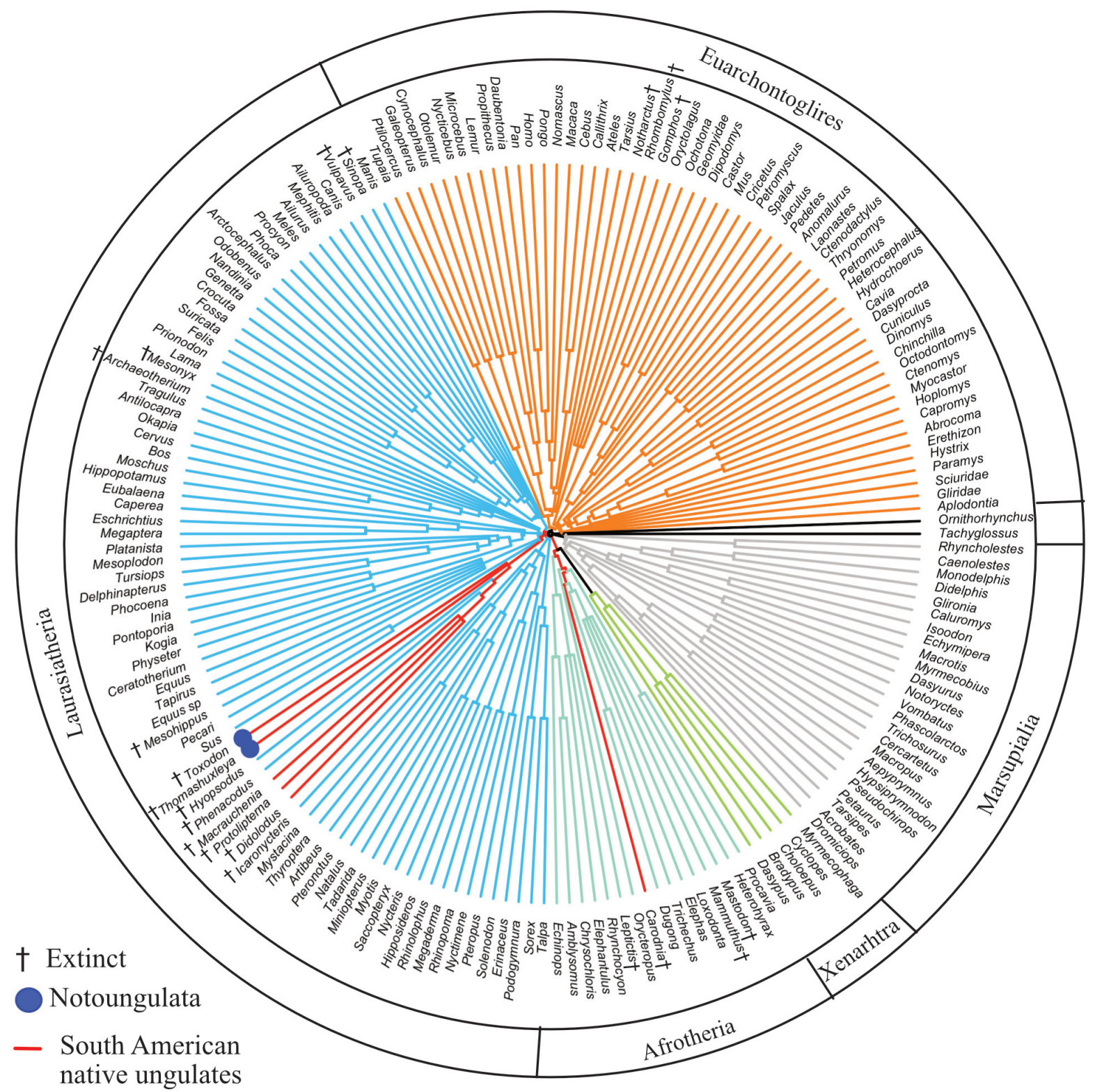

FIGURE 10. Strict consensus of 620 trees, 122391 steps in length from parsimony analysis of combined proteomic and morphological data constraining monophyly of each of two clades (but not both together): Notoungulata (i.e., Thomashuxleya and Toxodon) and Litopterna (i.e., Protolipterna and Macrauchenia).

al., 2014) indicate that independent runs did not converge on an optimal topology. The posterior probabilities of the South American fossil taxa with other placentals are low (Figure 11). The unconstrained Bayesian topology shows Thomashuxleya as the sister taxon of Xenarthra with a posterior probability of 0.62 , Protolipterna and Didolodus as the sister group to Afrotheria (0.88), and Carodnia in a clade with Loxodonta (0.79). Finally, Toxodon and Macrauchenia form a clade which appears as the sister taxon of Perissodactyla with a posterior probability of 0.63 .

The same dataset analysed constrained to support Notoungulata (Thomashuxleya and Toxodon) and Litopterna (Macrauchenia and Protolipterna), as above for MP, yielded an average standard deviation of split frequencies of 0.034 after $3,500,000$ generations. The $50 \%$ majority rule consensus of the post burn-in topologies (Figure 12) shows Notoungulata and Litopterna as sister clades with a posterior probability of 1 . The clade 
TABLE 6. Results from the Wilcoxon signed ranks test comparing topologies carried out in PAUP. Meridungulata $=$ constraint with all SANUs within a clade; N/L= Notoungulata (Thomashuxleya, Toxodon) and Litopterna (Macrauchenia, Protolipterna) monophyly constraints for each clade (but not both together); $p$ values greater than 0.05 indicate no difference between optimal and competing topology.

\begin{tabular}{cccccc}
\hline Topology & Tree length & Rank sums & $\mathbf{N}$ & $\mathbf{z}$ & $\mathbf{p}$ \\
\hline N/L & 122374 & (best) & & & \\
Meridungulata & 122391 & $52385.0 /--48640.0$ & 449 & -0.77 & 0.4390 \\
\hline
\end{tabular}

(Notoungulata, Litopterna) appears as sister group of Perissodactyla (0.62) and Carodnia is within Afrotheria as sister taxon of Loxodonta (0.95) (Figure 12).

\section{DISCUSSION}

\section{Cranioskeletal Anatomy}

The completeness of MPEF-PV 8166 offers a unique opportunity to study the skeletal anatomy of $T$. externa in detail, and provides the first unambiguous associations of cranial and postcranial material from one individual. Dental similarities are substantial among the isotemnids Thomashuxleya, Pleurolystodon, Anisotemnus, and Periphragnis (Simpson, 1967), but the dental morphology along with size allowed us to refer MPEF-PV 8166 to $T$. externa. We noted morphological differences in several postcranial elements of MPEF-PV 8166 when compared with other specimens previously referred to this species. In particular, we noted differences in the scapulae, humeri, ulnae, and radii in comparison with AMNH 28905, which was used in O'Leary et al. (2013) to code postcranial characters of this species.

Although incomplete, the astragalus of MPEFPV 8166 is of particular importance due to its association with craniodental remains. It is slightly smaller than AMNH 142463 referred to T. externa by Shockey and Flynn (2007). When compared with other astragali referred to Isotenmidae (Table 5 ), we found some differences that might indicate species specific characters within this group, such as the relatively high medial and lateral borders of the trochlea, and the relative width of the trochlea in relationship with the astragalar length. Thomashuxleya astragali (MPEF-PV 8166 and AMNH 142463) are considerably larger than other specimens variably assigned to this genus (e.g., $\mathrm{AMNH}$ 28690, AMNH 142464, and AMNH FM 14501), which therefore probably do not belong to Thomashuxleya.

\section{Body Size}

Regression equations obtained from dental variables yielded the highest estimates of body mass of MPEF-PV 8166 (Appendix 1), with an arithmetic mean of $556.4 \mathrm{~kg}$. Other subsets of measurements differed in their estimates: craniomandibular variables gave a mean of $126 \mathrm{~kg}$, limbs yielded a mean of $143.2 \mathrm{~kg}$, multivariate regression equations that included dental variables yielded a mean of $180.5 \mathrm{~kg}$ (Appendix 2), and the body mass estimate of the astragalus was $84 \pm 24.2 \mathrm{~kg}$.

For Isotemnidae, Elissamburu (2012) favored estimations obtained from dental measurements. The dental dimensions can be influenced by differences in function and diet, which challenges their use to estimate the body mass in fossil mammals with no living descendants. Damuth (1990) noted that Paleogene ungulates from North America tend to have larger teeth relative to their body mass than extant ungulates. Considering the values obtained from the postcranial bones, we believe dental dimensions overestimate the body mass of MEPF-PV 8166 (Appendix 1).

Proximal limb bones are good estimators of body mass because they are weight-bearing elements, subject to biomechanical constrains (Scott, 1990). Elissamburu (2012) considered some postcranial measurements to be good estimators of body mass for Thomashuxleya, but not for closely related taxa such as Pleurostylodon, which is odd given the comparable dimensions and anatomy of both taxa. MEPF-PV 8166 and other specimens referred to Thomashuxleya show robust limbs. MEPF-PV 8166 exhibits some morphological features which are suggestive of scratch-digging capabilities, such as a high spine of the scapula, a large humeral deltopectoral crest that extends distally, and a long ulnar olecranon (Shockey et al., 2007). Fossorial habits have been inferred in mesotheriids (Shockey et al., 2007), and other notoungulates (e.g., Protypotherium) show features that suggest digging capabilities (Croft and Anderson, 2008). Fossorial habits may be an ancestral attribute in notoungulates (Shockey et 


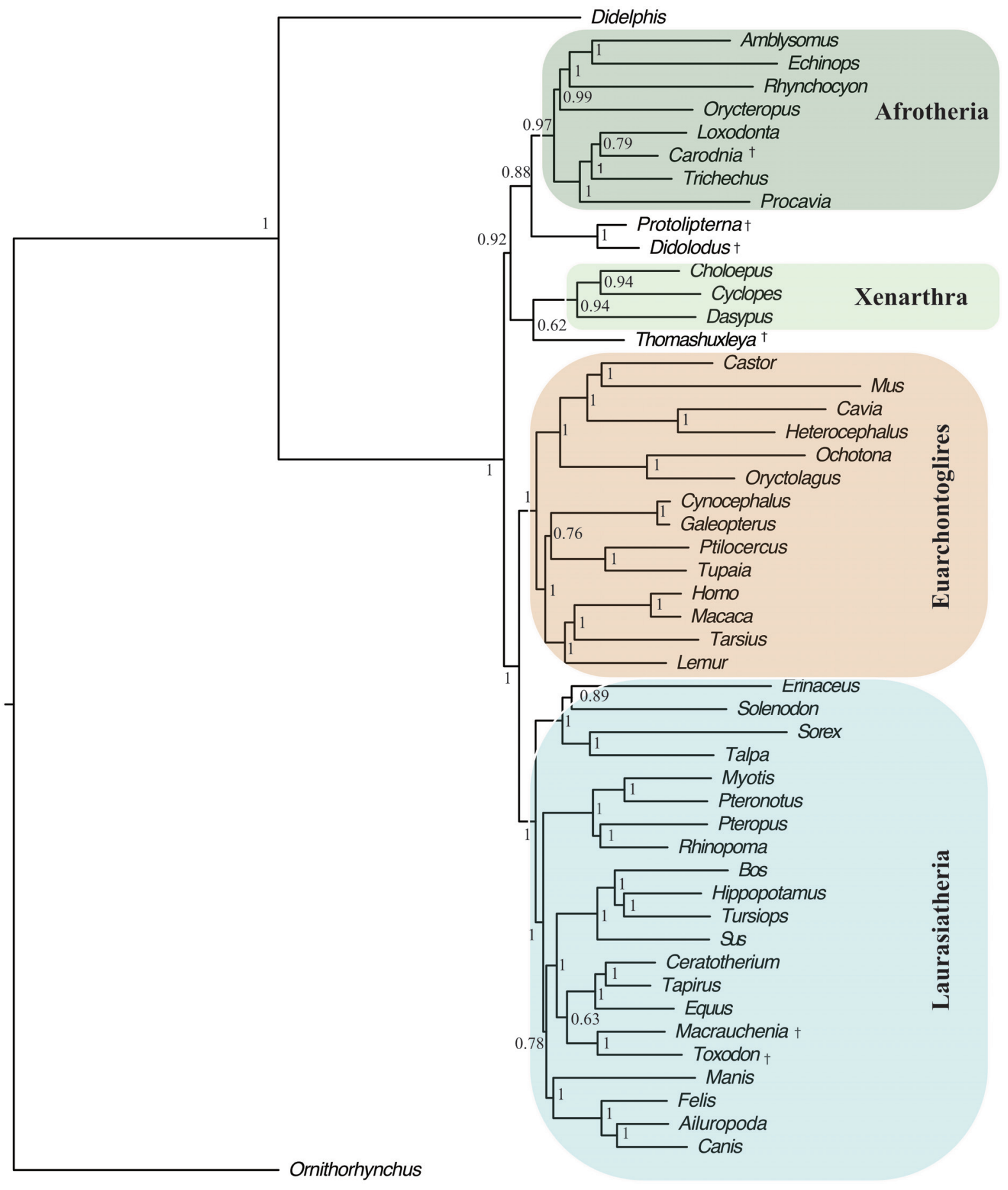

0.1

FIGURE 11. Optimal Bayesian tree (i.e., 50\% majority rule of post-burn-in trees) of combined proteomic and morphological data. Numbers represent Bayesian posterior probabilities; daggers indicate fossil taxa. 


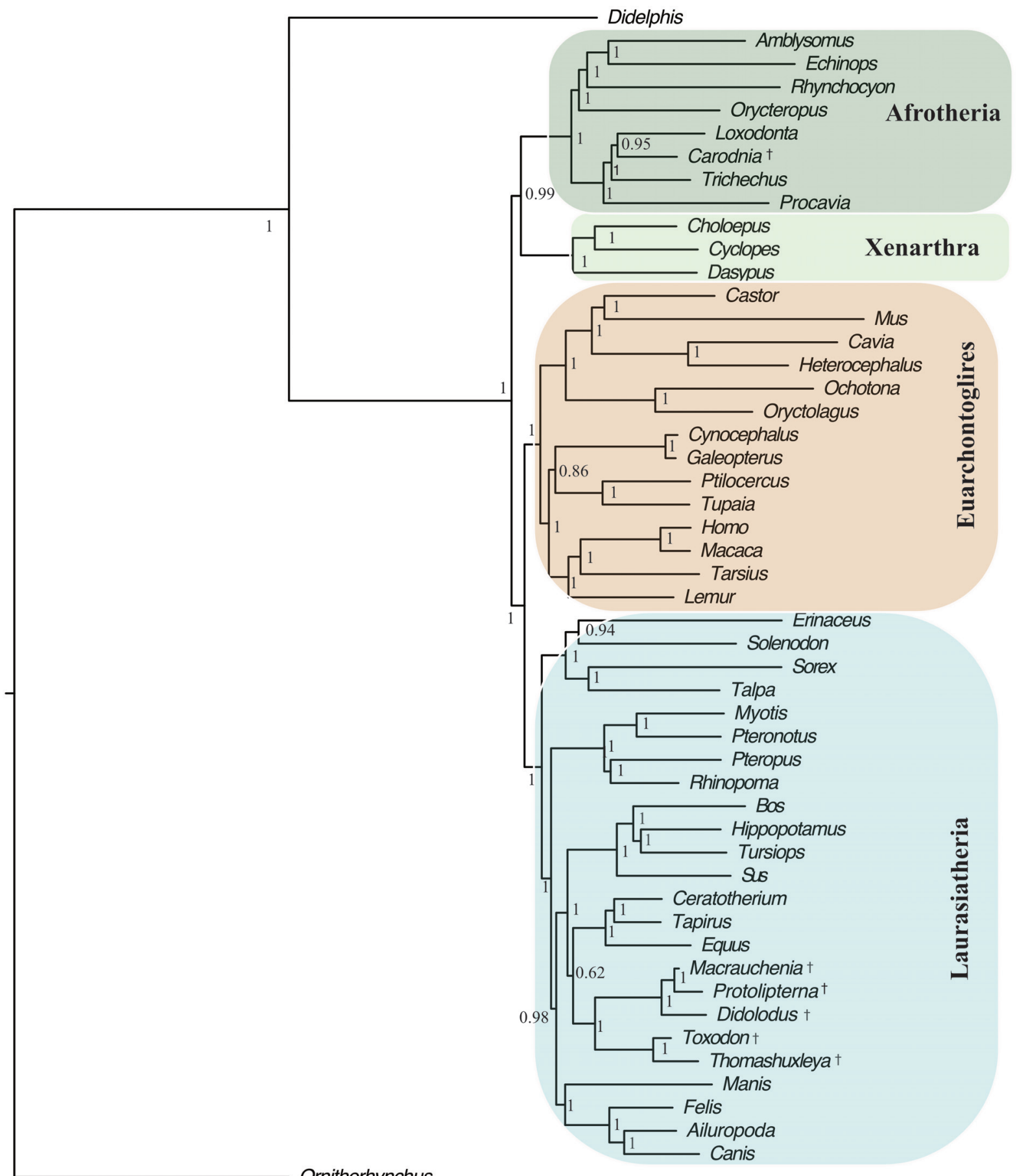

Ornithorhynchus

$$
0.1
$$

FIGURE 12. Optimal Bayesian tree (i.e., 50\% majority rule of post-burn-in trees) of combined proteomic and morphological analysis constraining monophyly of each of two clades (but not both together): Notoungulata (i.e., Thomashuxleya and Toxodon) and Litopterna (i.e., Protolipterna and Macrauchenia). Numbers represent Bayesian posterior probabilities; daggers indicate fossil taxa. 
al., 2007; Croft and Anderson, 2008), and if this is the case, limb bones could also overestimate the body size in notoungulates. The estimates obtained from postcranial measurements (mean $143.2 \mathrm{~kg}$ ) are higher than the estimate of $70-90 \mathrm{~kg}$ for Thomashuxleya of Croft (2016). This estimate was based on a value of ca.1.5 m of head-body length based on Simpson's skeletal reconstruction (Croft, personal commun., 2017). In extant ungulates, the regression of head-body length shows the highest correlation with body mass and lowest percent of prediction error (Damuth, 1990).

The body mass estimate from the astragalus $(84 \pm 24.2 \mathrm{~kg})$ is congruent with the estimate of 70 $90 \mathrm{~kg}$ of Croft (2016) based on the estimated headbody length of Thomashuxleya. Astragalar regression equations of Tsubamoto (2014) are based on a broad taxonomic sample of mammals, whereas the regression equations using limb bones presented by Scott (1990) are based on living ungulates (artiodactyls and perissodactyls). Of the variety of body mass estimates for MEPF-PV 8166 , we favor the one from the astragalus as it is based on a broader taxonomic sample of living mammals, and taken into account that morphological features in the limb bones associated with scratch-digging capabilities might bias the body mass estimate of MEPF-PV 8166.

$T$. externa is one of the largest mammalian taxa of the Vacan (Cifelli, 1985), only comparable in size with the astrapothere Albertogaudrya, according to the length of the lower molars. $T$. externa is the earliest known, anatomically welldocumented todoxodontian notoungulate (Billet, 2011; Deraco and García-López, 2015). Basal notoungulates such as Henricosbornia, which also occur in the Vacan but with an origin in at least the Itaboraian (early Eocene; 53-50 Ma; Gelfo et al., 2009; Woodburne et al., 2014a), were much smaller. For example, the m2 length of Henricosbornia waitehor from the Rio Chico Formation (Simpson, 1935) comprises less than a quarter of the $\mathrm{m} 2$ length in MPEF-PV 8166. With an estimated body mass of $\sim 84 \mathrm{~kg}$, Thomashuxleya demonstrates a large range of notoungulate body masses by the middle Eocene, and its postcranial morphology can be expected to reflect weightbearing adaptations.

To our knowledge, of the more than 150 species recognized for notoungulates, bone histology is documented in only four (de Ricqlès et al., 2009; Tomassini et al., 2014, 2015, 2017; Forasiepi et al., 2015; Kolb et al., 2015b). As in Thomashuxleya, the toxodontians Toxodon and Nesodon showed
Haversian bone with a compact cortex, a feature associated with the increased loading in large-bodied mammals (Straehl et al., 2013; Forasiepi et al., 2015; Kolb et al., 2015b; Tomassini et al., 2015). The presence of an outer circumferential layer (OCL) in the histological section of MPEF-PV 8166 indicates the specimen represents a skeletally mature individual of $T$. externa. At least some wear is evident on all of its dental loci, although compared to other Vacan specimens (and indeed Paleogene SANUs in general; see Strömberg et al., 2013) the degree of wear is fairly low.

Houssaye et al. (2016) analysed the bone microstructure of several SANUs including the toxodontid Nesodon. The femora of this taxon showed a large open medullary cavity surrounded by a spongious zone. A qualitative and quantitative analysis of the bone microstructure strongly suggest graviportality for Nesodon (Houssaye et al., 2016), based on the relatively high bone compactness and cortex thickness, and its position in a bone microstructure morphospace close to graviportal living mammals such as the rhinos Ceratherium and Dicerorhinus.

\section{Systematics}

The craniodental anatomy of MEPF-PV 8166 is similar to other specimens previously referred to Thomashuxleya. The completeness of the new Thomashuxleya specimen enable us to revise and add to data known for this taxon in a phylogenetic analysis within Notoungulata and within Placentalia. The craniodental anatomy of MEPF-PV 866 supports the placement of Thomashuxleya as an early divergent taxon within Toxodontia (Billet, 2011; Deraco and García-López, 2015). Some alleged synapomorphies that have previously been used to link SANUs with Afrotheria (Agnolin and Chimento, 2011) have already been convincingly refuted (Billet and Martin, 2011; Kramarz and Bond, 2014). Other studies group early members of Litopterna and South American "condylarths" with certain North American "condylarths"(Muizon and Cifelli, 2000; Gelfo, 2007) apparently a part of Laurasiatheria (Halliday et al., 2017). O'Leary et al. (2013) placed Thomashuxleya and Carodnia within Afrotheria, and Didolodus and Protolipterna within Laurasiatheria. Halliday et al. (2017) included Protolipterna and the notoungulate Simpsonotus in a comprehensive phylogenetic study of Paleocene placentals. In their study, Protolipterna was closely related to archaic artiodactyls, but the position of Simpsonotus was inconsistent, varying among different placental clades. 
Welker et al. (2015) presented a new source of data to address this question in a pioneering study that used collagen protein sequences from two Pleistocene species to test the phylogenetic affinities of meridiungulates. They hypothesized that at least some of South America's endemic mammalian groups are close relatives of Perissodactyla. Previous authors (e.g., Billet, 2011; Cifelli, 1993; Gelfo, 2007; Horovitz, 2004; Muizon and Cifelli, 2000; Simpson, 1936, 1967) have shown that the two most speciose groups (notoungulates and litopterns) are ungulate-grade placentals; thanks to the novel data from Welker et al. (2015), we can now attempt a greater level of precision.

To fully evaluate the impact of the new material (if any) on the estimation of the relationships of Thomashuxleya, at least some integration of biomolecular and gross anatomical data is necessary. The matrix of O'Leary et al. (2013) is, to date, the largest available anatomical matrix that also samples at least some meridiungulates, and we have improved on their coding based on the new material described here. Further progress will be gained once the comprehensive matrix of O'Leary et al., 2013 is revised in both definitions and character codings; our study has made a start on the latter. The multiple analyses we perform is also a case study in which different data sources are integrated and results are evaluated from multiple perspectives. We believe that the combination of morphological and molecular data can provide more precise and robust hypotheses for several extinct clades of mammals (e.g., Asher et al., 2005; Muizon et al., 2015; Pattinson et al., 2015), and we further note that combination of molecular and morphological datasets can in principle increase support for clades not present when one or both are analysed in isolation (Gatesy and Baker, 2005; Lee and Camens, 2009; Thompson et al., 2012).

On the other hand, we do not maintain that combination of phylogenetic data from multiple sources (e.g., collagens from recent taxa, morphology from ancient fossils) will in every case yield a well-supported topology. The variety of optimality criteria we have applied to our analysis of phylogenetic data including meridiungulates and modern taxa does not confirm either the relationship proposed by Welker et al. (2015) with Perissodactyla, nor does it rule out alternatives that place one or more SANUs close to Afrotheria, Euungulata, or even Xenarthra. The strict consensus of our most parsimonious trees split Notoungulata, placing Thomashuxleya within Afrotheria and Toxodon within Laurasiatheria (Figure 9). The post-burnin, majority rule consensus of our optimal Bayesian trees place Thomashuxleya as the sister taxa of Xenarthra (with a very low posterior probability) and Didolodus, Protolipterna, and Carodnia in or near Afrotheria (also with low posterior probabilities; Figure 11). The monophyly of Notoungulata and Litopterna is supported by morphological data of the extensive fossil record of these two groups. The MP and Bayesian analyses constrained to support the monophyly of Notoungulata (Toxodon and Thomashuxleya) and Litopterna (Macrauchenia and Protolipterna) recovered these clades within Laurasiatheria (Figure 10 and 12), a result that approximates the hypothesis of Welker et al. (2015) that one or more meridiungulate groups are closely related to Perissodactyla.

There are a number of causes potentially behind this lack of a confident resolution of the phylogenetic relationships of meridiungulates with other placentals. First, although the new Thomashuxleya specimen is one of the oldest and most complete notoungulate yet known, it is still a highly derived taxon, and its potential synapomorphies with any extant relatives have been at least partly overwritten by homoplasy. This possibility is demonstrably not the case for many vertebrate groups with an extensive Paleogene fossil record (e.g., primates as shown by Pattinson et al., 2015), but it is naive to expect that such a scenario has never happened during the course of mammalian evolution. Muizon et al. (2015) performed a phylogenetic analysis of placental interordinal relationships using morphological characters and including SANUs and a large sample of other Paleogene fossils. They pointed out the high level of homoplasy detected in their dataset, and our data also clearly demonstrate homoplasy (RI of 0.638 and $\mathrm{Cl}$ of 0.345 in our unconstrained tree).

Second, some part of the anatomy, which we have not yet sampled (e.g., inner ear), may yet contain key phylogenetic information with the potential to resolve the ambiguity discussed here (Macrini et al., 2010, 2013). An ear bone referred to an early divergent notoungulate shows that this region exhibits a mixture of plesiomorphic and derived features for Notoungulata (Billet and Muizon, 2013). The ear region of notoungulates exhibits similarities with hyracoids (Billet and Muizon, 2013), but further investigation is required to determine their phylogenetic implications. Finally, and non-exclusively, the early radiation of Notoungulata and other SANUs occurred very rapidly on parts of the continent which are not yet well sampled. Early Paleogene localities (e.g., Tiupampa, Itaborai) 
older than Cañadón Vaca exist, but have not yet yielded well-preserved, associated remains of notoungulates. Although it is a Xenungulate and not a notoungulate, Carodnia is a notable exception, comprising another large, Eocene meridiungulate known from associated cranial and postcranial remains from Itaborai, Brazil. Accordingly, phylogenetic uncertainty may dissipate with the inclusion of additional anatomical characters (e.g., those derived from CT imaging) and with the discovery of more complete notoungulate material predating the Eocene. Further extraction of durable protein sequences from other meridiungulates, even those that predate the Neogene, remains theoretically possible and is clearly among the most promising avenues for further research into meridiungulate systematics (cf., Welker et al., 2015).

\section{CONCLUSIONS}

MPEF-PV 8166 is one of the oldest, most complete associated notoungulate skeletons yet documented in the literature. We refer this specimen to $T$. externa based on dental morphology and size. The presence of an associated dentition with postcrania enables us to recognize variation in skeletal elements previously assigned to this taxon. $T$. externa weighed approximately $84 \pm 24.2$ $\mathrm{kg}$. Dental measurements provided larger estimates for body mass than skeletal elements. $T$. externa demonstrates that notoungulates acquired large size by the middle Eocene, and its bone histology shows that MPEF-PV 8166 was a skeletally mature individual with the capacity to withstand heavy loading, despite its incompletely fused femoral epiphyses. Our phylogenetic analysis raises a number of possibilities regarding its affinities. With Thomashuxleya constrained to be part of a monophyletic Notoungulata, MP recovers Thomashuxleya near the base of euungulates, close (but not on the stem) to Perissodactyla, whereas Bayesian analysis places it on the stem to Perissodactyla. Unconstrained MP and a Bayesian analysis splits meridiungulates into two groups: Pleistocene taxa known for collagen proteins with euungulates, and Paleogene taxa with afrotherians and xenarthrans.

\section{ACKNOWLEDGEMENTS}

We thank A. Carlini, P. Carlini, M. Cenizo, M. Ciancio, D. Croft, J. Gelfo, F. Goin, and M. Sánchez-Villagra for their help in the field and collecting the specimen described here. We are particularly grateful to A. Carlini for his generous hospitality and leadership during our stays in
Argentina. M. Sánchez-Villagra kindly took some measurements and provided pictures of the skull. We are grateful to A. Carlini, M. Sánchez-Villagra, A. Forasiepi, E. Amson, and C. Pimiento, M. Geiger, and the Evolutionary Morphology and Palaeobiology of Vertebrates group in Zürich for valuable comments. We thank T. Scheyer and C. Kolb for assistance in the preparation and discussion of the histology sections. S. Lukac made the reconstruction of Thomashuxleya. We thank J. Gelfo, M. Lorente, D. Croft and an anonymous reviewer for their comments that greatly improved the manuscript. J. Carrillo was supported by Swiss National Fund P1ZHP3_165068, and SNF 31003A-149605 to M.R. Sánchez-Villagra, and the University of Cambridge Newton Trust and the Leverhulme Trust to R.J. Asher.

\section{REFERENCES}

Agnolin, F.L. and Chimento, N.R. 2011. Afrotherian affinities for endemic South American "ungulates." Mammalian Biology - Zeitschrift für Säugetierkunde, 76 (2):101-108. doi: dx.doi.org/10.1016/j.mambio.2010.12.001

Ameghino, F. 1897. Les mammifêres crétacés de l'Argentine: deuxiême contribution â la connaissance de la faune mammalogique des couches â Pyrotherium. Boletin Instituto Geografico Argentino, 18:406521.

Ameghino, F. 1901. Notices préliminaries sur des ongulés nouveaux des terrains Crétacés de Patagonie. Boletín de la Academia Nacional de Ciencias de Córdoba, 16:1-349.

Ameghino, F. 1902. Notice préliminaires sur des mammiferes nouveaux des terrains crétacés de Patagonie. Boletín de la Academia Nacional de Ciencias de Córdoba, 17:5-70.

Ameghino, F. 1904a. Nuevas especies de mamíferos, cretáceos y terciarios de la República Argentina. Anales de la Sociedad Científica Argentina, 56-58:1142.

Ameghino, F. 1904b. La perforación astragaliana en los mamíferos no es un carácter originariamente primitivo. Anales del Museo Nacional de Buenos Aires, 3:349-460.

Asher, R.J. 2007. A web-database of mammalian morphology and a reanalysis of placental phylogeny. BMC Evolutionary Biology, 7:108. doi: 10.1186/1471-2148-7-108

Asher, R.J., Emry, R.J., and McKenna, M.C. 2005. New material of Centetodon (Mammalia, Lipotyphla) and the importance of (missing) DNA sequences in systematic paleontology. Journal of Vertebrate Paleontology, 25(4):911-923.

Barnosky, A.D. and Lindsey, E.L. 2010. Timing of quaternary megafaunal extinction in South America in relation to human arrival and climate change. Quaternary 
International, 217:10-29.

doi: dx.doi.org/10.1016/j.quaint.2009.11.017

Bellosi, E.D. and Krause, J.M. 2014. Onset of the Middle Eocene global cooling and expansion of open-vegetation habitats in central Patagonia. Andean Geology, 41 (1):29-48.

Bergqvist, L.P. Furtado, M.R., de Souza, C.P., and Powell, J.E. 2007. Colbertia magellanica (Bacia de Itaboraí, Brasil) e Colbertia lumbrerense (Grupo Salta, Argentina): a morfologia pós-craniana confrontada, p. 765-775. In Carvalho, I.S., Cassab, R.C., Schwanke, C., Carvahlo, A.A.C.S., Fernandes, M., Rodrigues, M.A.C,. Carvalho, M.S.S., and Oliveira, M.E.Q. (eds.), Paleontologia: Cenários de Vida. Vol 1. Editora Interciencia.

Billet, G. 2010. New observations on the skull of pyrotherium (pyrotheria, mammalia) and new phylogenetic hypotheses on South American ungulates. Journal of Mammalian Evolution, 17:21-59. doi: 10.1007/ s10914-009-9123-0

Billet, G. 2011. Phylogeny of the notoungulata (mammalia) based on cranial and dental characters. Journal of Systematic Palaeontology, 9:481-497. doi: $10.1080 / 14772019.2010 .528456$

Billet, G. and Martin, T. 2011. No evidence for an afrotherian-like delayed dental eruption in South American notoungulates. Naturwissenschaften, 98(6): 509-517. doi: 10.1007/s00114-011-0795-y

Bininda-Emonds, O.R. P., Cardillo, M., Jones, K.E., MacPhee, R.D.E., Beck, R.M.D., Grenyer, R., Proce, S.A., Vos, A., Gittleman, J.L., and Purvis, A. 2007. The delayed rise of present-day mammals. Nature, 446:507-513. d oi:10.1038/nature05634

Buckley, M. 2015. Ancient collagen reveals evolutionary history of the endemic South American 'ungulates'. Proceedings of the Royal Society B, 282:20142671. doi: dx.doi.org/10.1098/rspb.2014.2671

Carlini, A.A., Ciancio, M., and Scillato-Yané, G.J. 2005. Los Xenarthra de Gran Barranca: mas de 20 a de historia. Actas del XVI Congreso Geológico Argentino, 4:419-424.

Cassini, G.H., Cerdeño, E., Villafañe, A.L., and Muñoz, N.A. 2012. Paleobiology of Santacrucian native ungulates (Meridiungulata: Astrapotheria, Litopterna and Notoungulata), p. 243-286. In Vizcaíno, S.F., Kay, R.F., and Bargo, M.S. (eds.), Early Miocene Paleobiology in Patagonia: High Latitude Paleocommunities of the Santa Cruz Formation. Cambridge University Press, Cambridge.

Cassini, G.H., Mendoza, M., Vizcaíno, S.F., and Bargo, M.S. 2011. Inferring habitat and feeding behaviour of early Miocene notoungulates from Patagonia. Lethaia, 44:153-165. doi:10.1111/j.1502-3931.2010.00231.x

Cerdeño, E., Vera, B., Schmidt, G.I., Pujos, F., and Quispe, B.M. 2012. An almost complete skeleton of a new Mesotheriidae (Notoungulata) from the late Miocene of Casira, Bolivia. Journal of Systematic Palae- ontology, 10(2):341-360.

doi: $10.1080 / 14772019.2011 .569576$

Cifelli, R.L. 1985. Biostratigraphy of the Casamayoran, early Eocene, of Patagonia. American Museum Novitates, 2820.

Cifelli, R.L. 1993. The phylogeny of the native South American ungulates, p. 195-216. In Szalay, F.S., Novacek, M.J., and McKenna, M.C. (eds.), Mammal Phylogeny Placentals. Springer-Verlag, New York.

Cione, A.L., Tonni, E.P., and Soibelzon, L. 2003. The broken zig-zag: late Cenozoic large mammal and tortoise extinction in South America. Revista del Museo Argentino de Ciencias Naturales, 51(1):1-19.

Croft, D. A. 1999. Placentals: endemic South American ungulates, p. 890-906. In Singer, R. (ed.), The Encyclopedia of Paleontology. Fitzroy-Dearborn Publisher, Chicago.

Croft, D.A. 2016. Horned Armadillos and Rafting Monkeys. The Fascinating Fossil Mammals of South America. Indiana University Press, Bloomington and Indianapolis.

Croft, D.A. and Anderson, L.C. 2008. Locomotion in the extinct notoungulate Protypotherium. Paleontologia Electronica, 11(1):1-20.

Croft, D.A. Flynn, J.J., and Wyss, A.R. 2004. Notoungulata and Litopterna of the early Miocene Chucal fauna, northern Chile. Fieldiana Geology, 50:1-52.

Damuth, J. 1990. Problems in estimating body masses of archaic ungulates using dental measurements, $p$. 229-253. In Damuth, J. and MacFadden, B.J. (eds.), Body Size in Mammalian Paleobiology: Estimation and Biological Implications. Cambridge University Press, Cambridge.

Deraco, V. and García-López, D.A. 2015. A new Eocene Toxodontia (Mammalia, Notoungulata) from northwestern Argentina. Journal of Vertebrate Paleontology, e1037884. doi: 10.1080/02724634.2015.1037884

de Ricqlès, A., Taquet, P., and de Buffrenil, V. 2009. "Rediscovery" of Paul Gervais' paleohistological collection. Geodiversitas, 31:943-971. doi:10.5252/g2009n4a943

Elissamburu, A. 2012. Estimación de la masa corporal en géneros del Orden Notoungulata. Estudios Geológicos, 68:91-111. doi:10.3989/egeol.40336.133

Farris, J.S. 1989. The retention index and the rescaled consistency index. Cladistics, 5:417-419.

Foley, N.M., Springer, M.S., and Teeling, E.C. 2016. Mammal madness: is the mammal tree of life not yet resolved? Philosophical transactions of the Royal Society of London. Series B, Biological Sciences, $331: 20150140$ doi:10.1098/rstb.2015.0140

Forasiepi, A., Cerdeño, E., Bond, M., Schmidt, G., Naipauer, M., Straehl, F., Martinelli, A., Garrido, A., Schmitz, M., and Crowley, J. 2015. New toxodontid (Notoungulata) from the Early Miocene of Mendoza, Argentina. Paläontologische Zeitschrift, 89(3): 611- 
634.

doi:10.1007/s12542-014-0233-5

Gatesy, J. and Baker, R.H. 2005. Hidden likelihood support in genomic data: can forty-five wrongs make a right? Systematic Biology, 54(3):483-492. doi: $10.1080 / 10635150590945368$

Geiger, M., Forasiepi, A.M., Koyabu, D., and SánchezVillagra, M.R. 2014. Heterochrony and post-natal growth in mammals - an examination of growth plates in limbs. Journal of Evolutionary Biology, 27(1):98-115. doi: 10.1111/jeb.12279

Gelfo, J.N. 2007. The 'Condylarth' Raulvaccia peligrensis (Mammalia: Didolodontidae) from the Paleocene of Patagonia, Argentina. Journal of Vertebrate Paleontology, 27(3): 651-660.

Gelfo, J.N., Goin, F.J., Woodburne, M.O., and Muizon, C.D. 2009. Biochronological relationships of the earliest South American Paleogene mammalian faunas. Palaeontology, 52:251-269. doi:10.1111/j.1475-4983.2008.00835.x

Giannini, N. and García-López D. 2014. Ecomorphology of mammalian fossil lineages: identifying morphotypes in a case study of endemic South American ungulates. Journal of Mammalian Evolution, 21:195212. doi:10.1007/s10914-013-9233-6

Goloboff, P.A. 2014. Extended implied weighting. Cladistics, 30(3):260-272. doi:10.1111/cla.12047

Goloboff, P.A., Carpenter, J.M., Arias, J.S., and MirandaEsquivel, D.R. 2008b. Weighting against homoplasy improves phylogenetic analysis of morphological datasets. Cladistics, 24(5):758-773. doi:10.1111/j.1096-0031.2008.00209.x

Goloboff, P.A., Farris, J.S., and Nixon, K.C. 2008a. TNT, a free program for phylogenetic analysis. Cladistics, 24(5):774-786. doi:10.1111/j.1096-0031.2008.00217.x

Halliday, T.J.D., Upchurch, P., and Goswami, A. 2017. Resolving the relationships of Paleocene placental mammals. Biological Reviews, 92(1):521-550. doi:10.1111/brv.12242

Horovitz, I. 2004. Eutherian mammal systematics and the origins of South American ungulates as based on postcranial osteology. Bulletin of Carnegie Museum of Natural History, 36:63-79.

doi:10.2992/01459058(2004)36[63:EMSATO]2.0.CO;2

Houssaye, A., Fernandez, V., and Billet, G. 2016. Hyperspecialization in some South American endemic ungulates revealed by long bone microstructure. Journal of Mammalian Evolution, 23:221-235. doi: 10.1007/s10914-015-9312-y

Janis, C. 1990. Correlation of cranial and dental variables with body size in ungulates and macropodoids, p. 255-299. In Damuth, J. and MacFadden, B.J. (eds.), Body Size in Mammalian Palaeobiology: Estimation and Biological Implications. Cambridge University Press, Cambridge.
Kay, R.F., Madden, R.H., Vucetich, M.G., Carlini, A.A., Mazzoni, M.M., Re, G.H., Heizler, M., and Sandeman, H. 1999. Revised geochronology of the Casamayoran South American land mammal age: climatic and biotic implications. Proceedings of the National Academy of Sciences, 96:13235-13240. doi:10.1073/pnas.96.23.13235

Kolb, C., Scheyer, T., Lister, A., Azorit, C., de Vos, J., Schlingemann, M., Rossner, G., Monaghan, N., and Sánchez-Villagra, M.R. 2015a. Growth in fossil and extant deer and implications for body size and life history evolution. BMC Evolutionary Biology, 15:19. doi:10.1186/s12862-015-0295-3

Kolb, C., Scheyer, T.M., Veitschegger, K., Forasiepi, A.M., Amson, E., Van der Geer, A.A.E. Van den Hoek Ostende, L.W., Hayashi, S., and Sánchez-Villagra, M.R. 2015b. Mammalian bone palaeohistology: a survey and new data with emphasis on island forms. PeerJ, 3:e1358. doi:10.7717/peerj.1358

Kramarz, A. and Bond, M. 2014. Critical revision of the alleged delayed dental eruption in South American "ungulates." Mammalian Biology - Zeitschrift für Säugetierkunde, 79(3):170-175. doi:dx.doi.org/10.1016/j.mambio.2013.11.001

Lanfear, R., Calcott, B., Ho, S.Y.W., and Guindon, S. 2012. PartitionFinder: combined selection of partitioning schemes and substitution models for phylogenetic analyses. Molecular Biology and Evolution, 29(6):1695-1701.

doi:dx.doi.org/10.1093/molbev/mss020

Lee, M.S.Y. and Camens, A.B. 2009. Strong morphological support for the molecular evolutionary tree of placental mammals. Journal of Evolutionary Biology, 22(11):2243-2257. doi:10.1111/j.1420-9101.2009.01843.x

Lorente, M., Gelfo, J.N., and López, G.M. 2014. Postcranial anatomy of the early notoungulate Allalmeia atalaensis from the Eocene of Argentina. Alcheringa: An Australasian Journal of Palaeontology, 38:398-411. doi:10.1080/03115518.2014.885199

Lorente, M. 2015. Desarrollo de modelos de asociación y clasificaciones de restos postcraneanos aislados de ungulados nativos del Paleoceno-Eoceno de América del Sur. Unpublished PhD thesis, Facultad de Ciencias Naturales y Museo de La Plata, Universidad de La Plata, La Plata, Argentina

MacFadden, B.J. 2005. Diet and habitat of toxodont megaherbivores (Mammalia, Notoungulata) from the late Quaternary of South and Central America. Quaternary Research, 64:113-124. doi:dx.doi.org/10.1016/j.yqres.2005.05.003

Madden, R.M. 1990. Miocene Toxodontidae (Notoungulata, Mammalia) from Colombia, Ecuador and Chile. Unpublished PhD thesis, Department of Biological Anthropology and Anatomy, Duke University

Madden, R.M. 2015. Hypsodonty in the South American fossil record, p. 12-59. In Madden, R.M. (ed.), Hypsodonty in Mammals: Evolution, Geomorphology and 
the Role of Earth Surface Processes. Cambridge University Press, Cambridge.

Maddison, W.P. and Maddison, D.R. 2016. Mesquite: a modular system for evolutionary analysis. Version 3.10 mesquiteproject.org

Martinez-Maza, C., Alberdi, M.T., Nieto-Diaz, M., and Prado, J.L. 2014. Life-history traits of the Miocene Hipparion concudense (Spain) inferred from bone histological structure. PLoS ONE, 9:e103708. doi:10.1371/journal.pone. 0103708

McKenna, M.C. and Bell, S.K. 1997. Classification of Mammals above the Species Level. Columbia University Press, New York.

Mendoza, M., Janis, C.M., and Palmqvist, P. 2006. Estimating the body mass of extinct ungulates: a study on the use of multiple regression. Journal of Zoology, 270:90-101. doi:10.1111/j.1469-7998.2006.00094.x

Meredith, R.W., Janečka, J.E., Gatesy, J., Ryder, O.A., Fisher, C.A., Teeling, E.C., Goodbla, A., Eizirik, E., Simão, T.L.L., Stadler, T., Rabosky, D.L., Honeycutt, R.L., Flynn, J.J., Ingram, C.M., Steiner, C., Williams, T.L., Robinson, T.J., Burk-Herrick, A.B., Westerman, M.,Ayoub, N.A., Springer, M.S., and Murphy, W.J. 2011. Impacts of the Cretaceous terrestrial revolution and KPG extinction on mammal diversification. Science, 334(6055):521-524. doi:10.1126/science. 1211028

Muizon, C. de, and Cifelli, R. 2000. The "condylarths" (archaic Ungulata, Mammalia) from the early Palaeocene of Tiupampa (Bolivia): implications on the origin of the South American ungulates. Geodiversitas, 22(1):47-150.

Muizon, C. de, Billet, G., Argot, C., Ladevèze, S., and Goussard, F. 2015. Alcidedorbignya inopinata, a basal pantodont (Placentalia, Mammalia) from the early Palaeocene of Bolivia: anatomy, phylogeny and palaeobiology. Geodiversitas, 37(4):397-634. doi:10.5252/g2015n4a1

Murphy, W J., Eizirik, E., Johnson, W.E., Zhang, Y.P., Ryder, O.A., and O'Brien, J. 2001. Molecular phylogenetics and the origins of placental mammals. Nature, 409(6820):614-618. doi:10.1038/35054550

O'Leary, M.A., Bloch, J.I., Flynn, J.J., Gaudin, T.J., Giallombardo, A., Giannini, N.P., Goldberg, S.L., Kraatz, B.P., Luo, Z-X., Meng, J., Ni, X., Novacek, M.J., Perini, F.A., Randall, Z.S., Rougier, G.W., Sargis, E.J., Silcox, M.T., Simmons, N.B., Spaulding, M., Velazco, P.M., Weksler, M., Wible, J.R., and Cirranello, A.L. 2013. The Placental mammal ancestor and the post$\mathrm{K}-\mathrm{Pg}$ radiation of placentals. Science, 339:662-667. doi: 10.1126/science.1229237

Pascual, R. 2006. Evolution and geography: the biogeographic history of South American land mammals. Annals of the Missouri Botanical Garden, 93:209$230 . \quad$ doi: 10.3417/00266493(2006)93[209:eagtbh]2.0.co;2

Patterson, B. 1977. A primitive pyrothere (mammalia, notoungulata) from the early Tertiary of Northwestern
Venezuela. Fieldiana Geology, 33(22):1-40. doi:10.5962/bhl.title.5225

Pattinson, D.J., Thompson, R.S., Piotrowski, A.K., and Asher, R.J. 2015. Phylogeny, paleontology, and primates: do incomplete fossil bias the tree of life? Systematic Biology, 64(2): 169-186. doi:10.1093/sysbio/syu077

Ponton, F., Elżanowski, A., Castanet, J., Chinsamy, A., Margerie, E.D., Ricqlès, A.D., and Cubo, J. 2004. Variation of the outer circumferential layer in the limb bones of birds. Acta Ornithologica, 39:137-140. doi: $10.3161 / 068.039 .0210$

R Core Team. 2016. R: A language and environment for statistical computing. R Foundation for Statistical Computing, Vienna, Austria.URL www.R-project.org/.

Rambaut, A., Suchard, M.A., Xie, D., and Drummond, A.J. 2014. Tracer v1.6. beast.bio.ed.ac.uk/Tracer

Ronquist, F., Huelsenbeck, J., and Teslenko, M. 2011. MrBayes 3.2 Manual: Tutorials and model summaries, downloaded 25 november 2016. mrbayes.sourceforge.net/manual.php

Ronquist, F., Teslenko, M., vand der Mark, P., Ayres, D.L., Darling, A., Höhna, S., Larget, B., Liu, L., Suchard, M.A., and Huelsenbeck, J.P. 2012. MrBayes 3.2: efficient Bayesian phylogenetic inference and model choice across a large model space. Systematic Biology, 61(3):539-542. doi:10.1093/sysbio/sys029

Roth, S. 1903. Los ungulados sudamericanos. Anales del Museo de La Plata 5.

Scott, K.M. 1990. Postcranial dimensions of ungulates as predictors of body mass, p. 301-335. In Damuth, J. and MacFadden, B.J. (eds.), Body Size in Mammalian Paleobiology: Estimation and Biological Implications. Cambridge University Press, Cambridge.

Scott, W.B. 1912. Mammalia of the Santa Cruz Beds. Volume VI, Paleontology. Part II Toxodonta, p. 111238. In Scott, W.B. (ed.), Reports of the Princeton University Expeditions to Patagonia, 1896-1899. Princeton University, E. Schweizerbart'sche Verlagshandlung (E. Nägele), Stuttgart.

Shockey, B.J. and Flynn, J.J. 2007. Morphological diversity in the postcranial skeleton of Casamayoran (?middle to late Eocene) notoungulata and foot posture in notoungulates. American Museum Novitates, 3601.

Shockey, B.J., Croft, D.A., and Anaya, F. Analysis of function in the absence of extant functional homologues: a case study using mesotheriid notoungulates (Mammalia). Paleobiology, 33(2): 227-247. doi:10.1666/05052.1

Simpson, G.G. 1935. Descriptions of the oldest known South American mammals, from the Rio Chico Formation. American Museum Novitates, 793.

Simpson, G.G. 1936. Skeletal remains and restoration of Eocene Entelonychia from Patagonia. American Museum Novitates, 826. 
Simpson, G.G. 1948. The beginning of the age of mammals. Part 1. Bulletin of the American Museum of Natural History, 91:1-232.

Simpson, G.G. 1967. The beginning of the age of mammals in South America. Part 2. Bulletin of the American Museum of Natural History, 137:1-260.

Simpson, G.G. 1978. Early mammals in South America: Fact, controversy, and mystery. Proceedings of the American Philosophical Society. 122:318-328.

Simpson, G.G. 1980. Splendid Isolation. The Curious History of South American Mammals. Yale University Press, New Haven and London.

Smith, J.B. and Dodson, P. 2003. A proposal for a standard terminology of anatomical notation and orientation in fossil vertebrate dentitions. Journal of Vertebrate Paleontology, 23(1):1-12.

doi:dx.doi.org/10.1671/0272 4634(2003)23[1:APFAST]2.0.CO;2

Straehl, F.R., Scheyer, T.M., Forasiepi, A.M., MacPhee, R.D., and Sánchez-Villagra, M.R. 2013. Evolutionary patterns of bone histology and bone compactness in xenarthran mammal long bones. PLOS ONE, 8:e69275. doi:10.1371/journal.pone.0069275

Strömberg, C.A.E., Dunn, R.E., Madden, R.H., Kohn, M.J., and Carlini, A.A. 2013. Decoupling the spread of grasslands from the evolution of grazer-type herbivores in South America. Nature Communications, $4: 178$. doi:10.1038/ncomms2508

Song, S., Liu, L., Edwards, S.V., and Wu, S. 2012. Resolving conflict in eutherian mammal phylogeny using phylogenomics and the multispecies coalescent model. Proceedings of the National Academy of Sciences, 109(37):14942-14947. doi: 10.1073/pnas.1211733109

Swofford, D.L. 2002. PAUP*. Phylogenetic Analysis Using Parsimony ("and other methods). Version 4. Sinauer Associates, Sunderland, Massachusetts.

Tarver, J.E., dos Reis, M., Mirarab, S., Moran, R.J., Parker, S., O'Reilly, J.E., King, B.L., O'Connell, M.J., Asher, J.R., Warnow, T., Peterson, K., Donoghue, P.C.J., and Pisani, D. 2016. The interrelationships of placental mammals and the limits of phylogenetic inference. Genome Biology and Evolution, 8(2): 330344. doi: $10.1093 / g b e / e v v 261$

Thompson, R.S., Bärmann, E.V., and Asher, R.J. 2012. The interpretation of hidden support in combined data phylogenetics. Journal of Zoological Systematics and Evolutionary Research, 50(4):251-263. doi:10.1111/j.1439-0469.2012.00670.x

Tomassini, R.L., Garrone, M.C., and Montalvo, C.I. 2017. New light on the endemic South American pachyrukhine Paedotherium Burmeister, 1888 (Notoungulata, Hegetotheriidae): taphonomic and paleohistological analysis. Journal of South American Earth Sciences, 73:33-41.doi: 10.1016/ j.jsames.2016.11.004

Tomassini, R.L., Miño-Boilini, A.R., Zurita, A.E., Montalvo, C.I., and Cesaretti, N. 2015. Modificaciones fosildiagenéticas en Toxodon platensis Owen, 1837 (Notoungulata, Toxodontidae) del Pleistoceno tardío de la provincia de Corrientes, Argentina. Revista Mexicana de Ciencias Geológicas, 32(2):283-292.

Tomassini, R.L., Montalvo, C.I., Manera, T., and Visconti G. 2014. Mineralogy, geochemistry and paleohistology of Pliocene mammals from the Monte Hermoso Formation (Argentina). Paedotherium bonaerense (Notoungulata, Hegetotheriidae) as a case study. Ameghiniana, 51:385-395. doi:10.5710/AMGH.01.07.2014.2737

Townsend, K.E.B. and Croft, D.A. 2008. Diets of notoungulates from the Santa Cruz Formation, Argentina: new evidence from enamel microwear. Journal of Vertebrate Paleontology, 28:217-230. doi:10.1671/0272-4634(2008)28[217:DONFTS]2.0.CO;2

Tsubamoto, T. 2014. Estimating body mass from the astragalus in mammals. Acta Palaeontologica Polonica, 59:259-265. doi: 10.4202/app.2011.0067

Welker, F., Collins, M.J., Thomas, J.A., Wadsley, M., Brace, S., Cappellini, E., Turvey, S.T., Reguero, M., Gelfo, J.N., Kramarz, A., Burger, J., Thomas-Oates, J., Ashford, D.A.,Ashton, P.D., Rowsell, K., Porter, D.M., Kessler, B., Fischer, R., Baessmann, C.,Kaspar, S., Olsen, J.V., Kiley, P., Elliott, J.A., Kelstrup, C.D., Mullin, V., Hofreiter, M., Willerslev, E., Hublin, J.J., Orlando, L., Barnes, I., and MacPhee, R.D.E. 2015. Ancient proteins resolve the evolutionary history of Darwin's South American ungulates. Nature, 522:81-84. doi: $10.1038 /$ nature 14249

Wilf, P., Cúneo, N.R., Escapa, I.H., Pol, D., and Woodburne, M.O. 2013. Splendid and seldom isolated: the paleobiogeography of Patagonia. Annual Review of Earth and Planetary Sciences, 41:561-603. doi:10.1146/annurev-earth-050212-124217

Woodburne, M.O., Goin, F.J., Bond, M., Carlini, A.A., Gelfo, J.N., López, G.M., Iglesias, A., and Zimicz, A.N. 2014a. Paleogene land mammal faunas of South America: a response to global climatic changes and indigenous floral diversity. Journal of Mammalian Evolution, 21:1-73. doi: $10.1007 / \mathrm{s} 10914-012-9222-1$

Woodburne, M.O., Goin, F.J., Raigemborn, M.S., Heizler, M., Gelfo, J.N., and Oliveira, E.V. 2014b. Revised timing of the South American early Paleogene land mammal ages. Journal of South American Earth Sciences, 54:109-119.

doi: dx.doi.org/10.1016/j.jsames.2014.05.003 


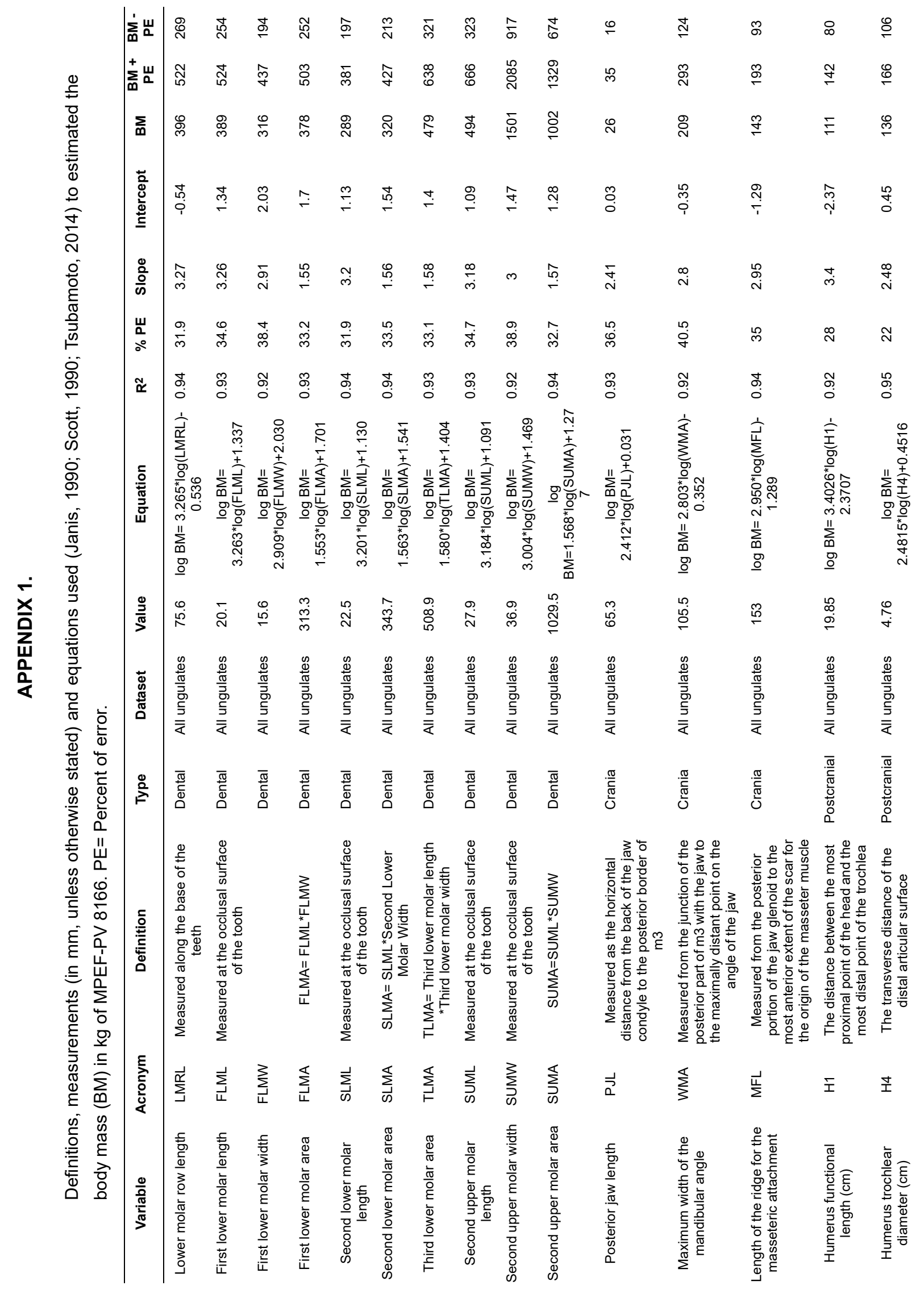




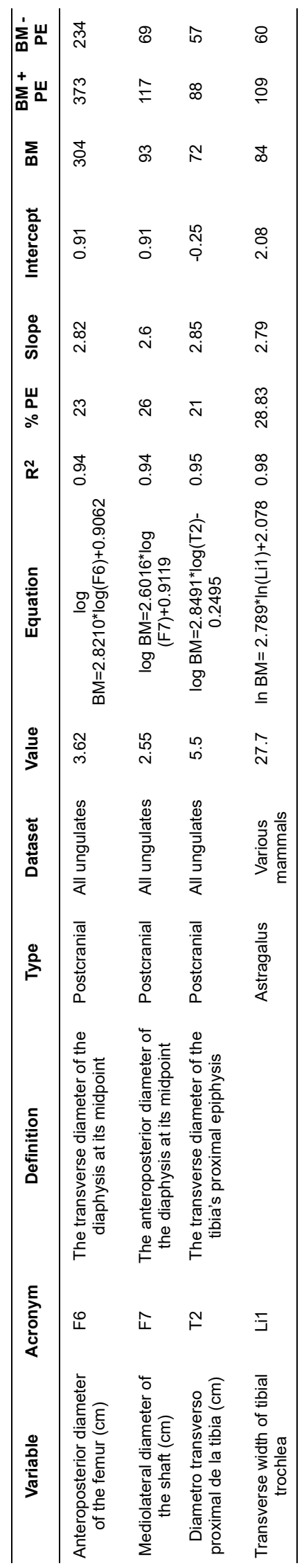




\section{APPENDIX 2.}

Selected measurement (in $\mathrm{cm}$ ) and multivariate equations used (Mendoza et al., 2006) to estimated the body mass in $\mathrm{kg}$ (BM) of MPEF-PV 8166.

\begin{tabular}{cccccccccccc}
\hline & & mid & & & & & & \multicolumn{3}{c}{ BM+ mid BM -mid } \\
Adj. R & \%MPE & PE & LMRL & LPRL & JMA & JMC & JD & JMB & BM & PE & PE \\
\hline 0.98 & $21-25$ & 23 & 7.56 & 5.86 & 6.53 & 10.55 & 4.88 & & 177 & 217 & 167 \\
0.98 & $21-25$ & 23 & 7.56 & 5.86 & 6.53 & 10.55 & 4.88 & 11.6 & 184 & 226 & 174 \\
\hline
\end{tabular}

